\title{
The equilibrium state of hydrogen in gallium nitride: theory and experiment
}

\author{
S. M. Myers, A. F. Wright, G. A. Petersen, C. H. Seager, W. R. Wampler, M. H Crawford, and
}

\author{
J. Han
}

Sandia National Laboratories

Albuquerque, New Mexico 87185-1056

\begin{abstract}
Formation energies and vibrational frequencies for $\mathrm{H}$ in wurtzite $\mathrm{GaN}$ were calculated from density functional theory and used to predict equilibrium state occupancies and solid solubilities for p-type, intrinsic, and n-type material. The solubility of deuterium (D) was measured at 600 $800^{\circ} \mathrm{C}$ as a function of $\mathrm{D}_{2}$ pressure and doping and compared with theory. Agreement was obtained by reducing the $\mathrm{H}$ formation energies $0.2 \mathrm{eV}$ from ab-initio theoretical values. The predicted stretch-mode frequency for $\mathrm{H}$ bound to the $\mathrm{Mg}$ acceptor lies $5 \%$ above an observed infrared absorption attributed to this complex. It is concluded that currently recognized $\mathrm{H}$ states and physical processes account for the equilibrium behavior of $\mathrm{H}$ examined in this work.
\end{abstract}




\section{DISCLAIMER}

This report was prepared as an account of work sponsored by an agency of the United States Government. Neither the United States Government nor any agency thereof, nor any of their employees, make any warranty, express or implied, or assumes any legal liability or responsibility for the accuracy, completeness, or usefulness of any information, apparatus, product, or process disclosed, or represents that its use would not infringe privately owned rights. Reference herein to any specific commercial product, process, or service by trade name, trademark, manufacturer, or otherwise does not necessarily constitute or imply its endorsement, recommendation, or favoring by the United States Government or any agency thereof. The views and opinions of authors expressed herein do not necessarily state or reflect those of the United States Government or any agency thereof. 


\section{DISCLAIMER}

Portions of this document may be illegible in electronic image products. Images are produced from the best available original document. 


\section{INTRODUCTION}

Hydrogen is introduced into GaN during growth by metal-organic chemical vapor deposition (MOCVD) and during various stages of subsequent device processing. (See, e.g., Ref. 1 and citations therein.) Uptake is especially pronounced in p-type material, typically resulting in a nearly complete neutralization of $\mathrm{Mg}$ acceptors after MOCVD growth. Reversal of this passivation is accomplished by thermal release of the $\mathrm{H}$ at elevated temperatures, 2,3 by minority-carrier injection at lower temperatures causing the $\mathrm{H}$ to transfer to a metastable, nonpassivating state, 4,5 or by electron irradiation. 6,7 Thermal-release from p-type material is retarded by the stability of the passivated state, which can cause retention of the $\mathrm{H}$ to temperatures where degradation of the semiconductor may occur. Conversely, $\mathrm{H}$ passivation during growth is believed to facilitate p-type doping by diminishing the driving forces for formation of electrically compensating defects such as the $\mathrm{N}$ vacancy. 8,9 The need to deal optimally with the varied and technologically important effects of $\mathrm{H}$ in GaN provides an impetus to understand its behavior.

The states of $\mathrm{H}$ in $\mathrm{GaN}$ were previously examined using density-functional theory, which was applied to both the metastable zincblende 10,11 and equilibrium wurtzite ${ }^{11}$ structures. It was concluded that $\mathrm{H}$ in interstitial solution can assume positive, neutral, and negative charges, with the neutral species being less stable than one or the other of the charged states for all Fermi energies. These theoretical studies also indicated that $\mathrm{H}$ forms a bound neutral complex with $\mathrm{Mg}$ acceptors, residing at an antibonding site of a $\mathrm{N}$ neighbor of the $\mathrm{Mg}$. The existence of this complex was reinforced by experimental observation of an infrared (IR) absorption consistent with a predicted local vibrational mode of the $\mathrm{H}^{1}{ }^{12}$ Interstitial $\mathrm{H}_{2}$ was predicted to be energetically preferred for a limited range of Fermi energies near the middle of the band gap. Diffusion activation energies obtained from density-functional theory indicated that $\mathrm{H}^{+}$and $\mathrm{H}^{0}$ are much more mobile than $\mathrm{H}^{-}$.

In the present investigation, we are modeling the behavior of $\mathrm{H}$ in defect-free, wurtzite GaN using ab-initio theory and are comparing the results with a range of experimental 
information. One objective is to assess quantitatively the extent to which experimental observations can be explained in terms of currently recognized atomic processes, thereby extending the largely qualitative interpretations of earlier studies. A second goal is to progress toward a reliably predictive model of $\mathrm{H}$ behavior that may ultimately facilitate improved processing of devices. Our theoretical approach has two parts. First, density-functional theory is employed to calculate the energy of $\mathrm{H}$ as a function of lattice position and charge state at zero temperature, thereby allowing energy minima, vibrational frequencies, and diffusion activation energies to be determined. Aspects of this work were reported previously. 11 The results are then used in diffusion-reaction theory to model the behavior of the $\mathrm{H}$ at elevated temperatures. Properties that are predicted and compared with experiment include the solubility of $\mathrm{H}$, its vibrational spectrum, the rate of uptake from $\mathrm{H}_{2}$ gas, and the rates of thermal release and associated dopant activation. In this article we deal with equilibrium state populations and the solubility of $\mathrm{H}$ at temperatures above $400^{\circ} \mathrm{C}$, where local equilibration among states is expected to be rapid. By including in detail the effects of $\mathrm{H}$ vibrations and degeneracies, our treatment of the absolute solubility goes beyond what has previously been done for semiconductors. The investigation encompasses p-type, $\mathrm{Mg}$-doped $\mathrm{GaN}$, intrinsic material, and n-type. Si-doped GaN, with particular attention being devoted to the case of $\mathrm{Mg}$ doping. A subsequent paper will discuss diffusion, uptake, release, and activation of dopants. A preliminary report of this work appeared previously. 13

\section{STATE ENERGIES FROM DENSITY-FUNCTIONAL THEORY}

Density functional theory was used to calculate the energy of $\mathrm{H}$ in wurtzite $\mathrm{GaN}$ as a function of lattice position and charge state at zero temperature, using methods detailed elsewhere. ${ }^{11}$ Hydrogen interactions with $\mathrm{Mg}$ acceptors and Si donors were included. The periodically repeated supercell employed in these calculations contained 72 atoms. and energyminimizing lattice relaxation was included. The results were used to identify the stable configurations of $\mathrm{H}$ and to evaluate the associated formation energies. In order to estimate $\mathrm{H}$ 
vibrational frequencies, we calculated restoring forces for small displacements of the $\mathrm{H}$ atom in orthogonal directions about the minimum-energy position with other atoms held fixed and diagonalized the resulting force-constant matrix. The frequency was then evaluated using the actual mass of the $\mathrm{H}$ atom rather than a reduced mass. Activation energies for diffusion of $\mathrm{H}^{+}$, $\mathrm{H}^{0}$, and $\mathrm{H}^{-}$along the $\mathrm{c}$-axis were obtained by consideration of multiple paths between neighboring stable sites with host-lattice relaxation taken into account.

In the case of $\mathrm{H}^{+}$, two nearly degenerate energy minima were identified having the configurations shown in Figs. 1(a) and 1(b). In one of these, $\mathrm{H}$ occupies a bond-center (BC) position along the c-axis of the hexagonal structure, while in the other, $\mathrm{H}$ is located at a $\mathrm{N}$ antibonding $(\mathrm{AB})$ site oriented transverse to the $\mathrm{c}$-axis. The bond-center position transverse to the $\mathrm{c}$-axis and the $\mathrm{N}$ antibonding configuration along the $\mathrm{c}$-axis both have significantly greater energy. The images in Fig. 1 show the computed atomic positions in orthographic projection, allowing the more pronounced lattice relaxations to be discerned from inspection. Especially evident is the movement of the electron-deficient $\mathrm{Ga}$ atoms away from the positive $\mathrm{H}$ atom. The minimum-energy configuration of the bound neutral $\mathrm{Mg}-\mathrm{H}$ complex is shown in Fig. $\mathrm{l}(\mathrm{c})$. The $\mathrm{H}$ occupies an antibonding site of a $\mathrm{N}$ neighbor of the $\mathrm{Mg}$, resembling the atomic arrangement of the $\mathrm{H}^{+}(\mathrm{AB})$ site. The $\mathrm{c}$-axis bond-center site adjacent to the $\mathrm{Mg}$ is unstable due to the relatively large size of $\mathrm{Mg}^{-}$, which results in an increased strain energy. In the neutral and negatively charged states, namely $\mathrm{H}^{0}, \mathrm{H}^{-}$, the $\mathrm{Si}-\mathrm{H}$ bound neutral complex, and $\mathrm{H}_{2}$, the $\mathrm{H}$ is predicted to reside centrally in the open c-axis channel, as shown in Figs. 1(d)- $1(\mathrm{~g})$. The neutral $\mathrm{H}$ atom is closer to the smaller, electron deficient $\mathrm{Ga}$ than to the larger, more electronegative $\mathrm{N}$. In the case of $\mathrm{H}^{-}$, this tendency is enhanced by electrostatic attraction, and there is a noticeable relaxation of $\mathrm{Ga}$ atoms toward the $\mathrm{H}$. The presence of $\mathrm{Si}^{+}$on the $\mathrm{Ga}$ sublattice produces a still greater attraction, and the resultant displacements of the $\mathrm{H}$ and $\mathrm{Si}$ are accordingly larger.

Table I lists zero-temperature formation energies, c-axis diffusion activation energies, and local-mode vibrational frequencies for the above $\mathrm{H}$ species as obtained from densityfunctional theory. While the diffusion activation energies do not bear directly on the equilibria 
considered in this paper, they are included for completeness and because they provide an indication of equilibration times. The reference condition for the formation energy, $\mathrm{E}^{f}$, consists of the neutral $\mathrm{H}$ atom in vacuum and $\mathrm{GaN}$ with all electrical dopants in the neutral state. The tabulated values of $\mathrm{E}^{\mathrm{f}}$ are for the particular case where the electron chemical potential, or Fermi energy, is at the valence-band edge, $\mathrm{EF}_{\mathrm{F}}=\mathrm{E}_{\mathrm{V}}$, and will be denoted $\mathrm{E}^{\mathrm{f}, 0}$; more generally,

$$
E^{f}\left(E_{F}\right)=E^{f, 0}+\sigma\left(E_{F}-E_{V}\right)
$$

where $\sigma$ is the integer charge state of the species. In the case of the neutral $\mathrm{Mg}-\mathrm{H}$ complex, the tabulated theoretical quantity is the binding energy relative to widely separated $\mathrm{H}^{+}$and $\mathrm{Mg}^{-}$; this energy is $-0.7 \mathrm{eV}$ independent of Fermi level. Similarly, for the neutral $\mathrm{Si}-\mathrm{H}$ complex, the binding energy of $0.3 \mathrm{eV}$ is relative to isolated $\mathrm{H}^{-}$and $\mathrm{Si}^{+}$. The diffusion activation energies in the table reflect the aforementioned property that $\mathrm{H}^{+}$and $\mathrm{H}^{0}$ are much more mobile than $\mathrm{H}^{-}$. The vibrational frequencies given for the three atomic configurations with $\mathrm{H}^{+}$bonded to $\mathrm{N}$ encompass, for each case, a single bond-stretching mode and two bending modes. While the bending modes are in principle not degenerate for the $\mathrm{N}$-antibonding orientation transverse to the $c$-axis, the actual difference between computed values is negligible and hence not listed.

Formation energies of the $\mathrm{H}$ states obtained from Eq. (1) and Table I are plotted as a function of Fermi energy in Fig. 2. Evaluation of the formation energy of the $\mathrm{Mg}-\mathrm{H}$ complex from the theoretical binding energy entails knowledge of the formation energy of $\mathrm{Mg}^{-}$relative to $\mathrm{Mg}^{0}$ for $\mathrm{E}_{\mathrm{F}}=\mathrm{E}_{\mathrm{V}}$. We take this ionization energy to be $0.16 \mathrm{eV}$, a widely used value representative of experimental results from electrical-property measurements. (See, e.g., Ref. 14 and citations therein.) We note, however, that values from 0.11 to $0.19 \mathrm{eV}$ have been reported, with the variation being attributed to the dependence of the ionization energy on acceptor concentration. ${ }^{14}$ Denoting the $\mathrm{Mg}-\mathrm{H}$ binding energy as $\Delta \mathrm{E}_{\mathrm{MgH}}$, one has

$$
E_{M g H}^{f}=E_{H+}^{f, 0}+E_{M g-}^{f, 0}+\Delta E_{M g H}=-3.21 e V
$$


independent of Fermi level. The formation energy for the $\mathrm{Si}-\mathrm{H}$ complex is obtained from $\Delta \mathrm{E}_{\mathrm{SiH}}$ in similar fashion, taking the ionization level of the Si donor to be $0.022 \mathrm{eV}$ below the conduction-band edge; 15,16 the resulting value is $-2.24 \mathrm{eV}$. Included for comparison in Fig. 2 is the formation energy per atom of $\mathrm{H}_{2}$ gas, which we have equated to $-2.24 \mathrm{eV}$ based on the experimentally determined dissociation energy of the molecule. ${ }^{17}$ Coincidentally, this energy is nearly identical to that for the $\mathrm{Si}-\mathrm{H}$ complex. Finally, for purposes of the discussion to follow, it is useful also to consider the formation energies expressed relative to the lowest energy states of the $\mathrm{Mg}$ acceptor and $\mathrm{Si}$ donor at any given Fermi level, rather than always using $\mathrm{Mg}^{0}$ and $\mathrm{Si}^{0}$ as the reference state. This difference in definition affects only the formation energies of the $\mathrm{Mg}-\mathrm{H}$ and $\mathrm{Si}-\mathrm{H}$ complexes, and then only for Fermi energies where the dopant is ionized; the result is given by the dashed lines in Fig. 2 .

The valence and conduction bands of wurtzite $\mathrm{GaN}$ were previously treated using density-functional theory, 18 and from the findings of that work we evaluated band densities-ofstates (DOS), thereby enabling the calculation of Fermi energy and carrier concentrations discussed in Section III. The resulting DOS are shown in Fig. 3. In the case of the conduction band, the DOS is nearly parabolic, reflecting a unique effective carrier mass of 0.18 electron masses $\left(\mathrm{m}_{\mathrm{O}}\right)$. This agrees well with recent experimental results. $19-21$ The valence band is more complicated, ${ }^{18,22,23}$ comprising multiple, anisotropic, nonparabolic lobes that combine to give the DOS shown in Fig. 3. We note that the near-edge effective mass for heavy holes obtained from density-functional theory is about $2 \mathrm{~m}_{0}, 23$ an exceptionally large value for semiconductors. Reported experiment results for the effective hole mass have varied considerably, and include, for example, a widely cited earlier determination of $0.8 \mathrm{~m}_{\mathrm{o}} 24$ and a recent, higher value of $2.2 \mathrm{~m}_{0} .25$ We conclude provisionally that the theoretical DOS for the valence band shown in Fig. 3 is consistent with available experimental information. 


\section{CALCULATION OF STATE OCCUPANCIES AND HYDROGEN SOLUBILITY}

The zero-temperature formation energies shown in Fig. 2 have several qualitative implications for the behavior of $\mathrm{H}$ in $\mathrm{GaN}$. These are discussed more readily using the lowestenergy states of the $\mathrm{Mg}$ acceptor and $\mathrm{Si}$ donor as the energy reference, so that for the $\mathrm{Mg}-\mathrm{H}$ and $\mathrm{Si}-\mathrm{H}$ complexes the dashed lines in the figure should be considered rather than the solid lines. When the Fermi level is close to the valence-band edge, both $\mathrm{H}^{+}$and the $\mathrm{Mg}-\mathrm{H}$ complex are predicted to be substantially lower in energy than $\mathrm{H}_{2}$ gas. This property is atypical among semiconductors, and it is attributable largely to the strength of the $\mathrm{N}-\mathrm{H}$ bond. It implies that $\mathrm{H}$ will go exothermically from the gas into solution in p-type material. As this process continues, $\mathrm{H}$ passivation of the $\mathrm{Mg}$ acceptor combined with electrical compensation by $\mathrm{H}^{+}$not attached to $\mathrm{Mg}$ will cause the Fermi level to rise, ultimately shifting the state energies to the point where uptake is no longer favored. Competition between the passivation and compensation of the $\mathrm{Mg}$ is governed by the opposing influences of the lower formation energy of the $\mathrm{MgH}$ complex and the higher entropy of the $\mathrm{H}^{+}$due to its larger number of available sites. An analogous situation arises in Si-doped GaN when the Fermi level is close to the conduction-band edge. but the $\mathrm{H}$ energies never reach the low level achieved in the p-type material. Another noteworthy property of the $\mathrm{H}$, one emphasized by previous investigators, 10,11 is that the relatively large formation energy of the neutral atom makes it unstable with respect to one or the other of the charged states for all positions of the Fermi level. This implies that $\mathrm{H}^{0}$ is never the principal constituent in solution. Finally, interstitial $\mathrm{H}_{2}$ is predicted to the most energetically stable $\mathrm{H}$ species in the defect-free lattice for a range of Fermi energies near the center of the band gap.

In order to describe the elevated-temperature behavior of $\mathrm{H}$ more quantitatively, we include in the $\mathrm{H}$ chemical potential not only the above formation energies, but also contributions from the local-mode vibrations of the $\mathrm{H}$ listed in Table I, the entropies of site occupation, and the spin degeneracies of neutral $\mathrm{H}, \mathrm{Mg}$, and $\mathrm{Si}$. Equations relating the equilibrium populations of $\mathrm{H}$ states are developed by considering detailed balance for a convenient subset of the reactions 
taking place in the system. Equating $\mathrm{H}$ chemical potentials for the two species in the reaction $\mathrm{H}^{0} \leftrightarrow \mathrm{H}^{+}(\mathrm{AB})$ gives

$$
\begin{aligned}
k T \ln \left(\frac{\left[\mathrm{H}^{+}(\mathrm{AB})\right]}{\left[\mathrm{H}^{0}\right]}\right)= & \left(\mathrm{E}_{\mathrm{H} 0}^{\mathrm{f}}-\mathrm{E}_{\mathrm{H}+}^{\mathrm{f}, 0}-\mathrm{E}_{\mathrm{F}}\right)+\left(\mu_{\mathrm{H} 0}^{\mathrm{vib}}-\mu_{\mathrm{AB}}^{\mathrm{vib}}\right) \\
& +k T \ln \left(\frac{\mathrm{Z}_{\mathrm{AB}}^{\mathrm{cfg}}}{\mathrm{Z}_{\mathrm{H} 0}^{\mathrm{cfg}}}\right)+k T \ln \left(\frac{\mathrm{Z}_{\mathrm{AB}}^{\mathrm{spn}}}{\mathrm{Z}_{\mathrm{H} 0}^{\mathrm{spn}}}\right)
\end{aligned}
$$

where $\mathrm{k}$ is the Boltzimann constant, $\mathrm{T}$ is the absolute temperature, square brackets denote concentration expressed as number per unit volume, $\mathrm{H}^{+}(\mathrm{AB})$ refers to $\mathrm{H}^{+}$at the $\mathrm{N}$ antibonding site as distinct from the bond center $(\mathrm{BC})$ site, $\mu_{\mathrm{i}}^{\mathrm{vib}}$ is the contribution to the chemical potential of species $\mathrm{i}$ from $\mathrm{H}$ vibrations, $\mathrm{Z}_{\mathrm{i}}^{\mathrm{cfg}}$ is the number of equivalent structural configurations per $\mathrm{N}$ atom, and $Z_{i}^{\text {spn }}$ is the spin degeneracy. The terms involving concentrations and degeneracies are discussed further in the Appendix. (See also the consideration of $\mathrm{H}$ thermodynamics in Ref. 26.) The $\mathrm{H}$ vibrational chemical potential, including both enthalpy and entropy parts, is given in the harmonic approximation by 27

$$
\mu_{i}^{\mathrm{vib}}=-k T \sum_{j} \ln \left(\frac{\exp \left(\frac{-h v_{i, j}}{2 k T}\right)}{1-\exp \left(\frac{-h v_{i, j}}{k T}\right)}\right)
$$

where $\mathrm{h}$ is Planck's constant and $v_{\mathrm{i}, \mathrm{j}}$ is the frequency for vibrational mode $\mathrm{j}$ of species $\mathrm{i}$ given in Table I. These quantities are plotted as functions of temperature in Fig. 4, where both the magnitudes and the temperature dependencies are seen to be far from negligible. From inspection of the configurations in Fig. $1, Z_{\mathrm{AB}}^{\mathrm{cfg}}=3$ and $\mathrm{Z}_{\mathrm{H} 0}^{\mathrm{cfg}}=1$. We assign spin degeneracies on the basis that the neutral $\mathrm{H}$ atom and the neutral dopants each have a single unpaired electron, which is removed upon ionization; accordingly, $\mathrm{Z}_{\mathrm{AB}}^{\mathrm{spn}}=1$ and $\mathrm{Z}_{\mathrm{H} 0}^{\mathrm{spn}}=2$. The equation relating 
$\left[\mathrm{H}^{+}(\mathrm{BC})\right]$ to $\left[\mathrm{H}^{0}\right]$ is analogous to Eq. (3), with $\mathrm{Z}_{\mathrm{BC}}^{\mathrm{cfg}}=1$ and $\mathrm{Z}_{\mathrm{BC}}^{\mathrm{spn}}=1$. Similarly, analysis of the reaction $\mathrm{H}^{0} \leftrightarrow \mathrm{H}^{-}$yields

$$
k T \ln \left(\frac{\left[\mathrm{H}^{-}\right]}{\left[\mathrm{H}^{0}\right]}\right)=\left(\mathrm{E}_{\mathrm{H} 0}^{\mathrm{f}}-\mathrm{E}_{\mathrm{H}-0}^{\mathrm{f}, 0}+\mathrm{E}_{\mathrm{F}}\right)+\left(\mu_{\mathrm{H} 0}^{\mathrm{vib}}-\mu_{\mathrm{H}-}^{\mathrm{vib}}\right)+\mathrm{kT} \ln \left(\frac{\mathrm{Z}_{\mathrm{H}-}^{\mathrm{spn}}}{\mathrm{Z}_{\mathrm{H} 0}^{\mathrm{spn}}}\right)
$$

with the configurational-degeneracy term being zero for this case and $\mathrm{Z}_{\mathrm{H}-}^{\mathrm{spn}}=1$. Considering the reaction $\mathrm{H}^{0}+\mathrm{Mg}^{0} \leftrightarrow \mathrm{MgH}$, which is mathematically more convenient than treating the physically more prevalent process $\mathrm{H}^{+}+\mathrm{Mg}^{-} \leftrightarrow \mathrm{MgH}$, one finds

$$
\begin{aligned}
k T \ln \left(\frac{[\mathrm{MgH}][\mathrm{N}]}{\left[\mathrm{H}^{0}\right]\left[\mathrm{Mg}^{0}\right]}\right)= & \left(\mathrm{E}_{\mathrm{H} 0}^{\mathrm{f}}-\mathrm{E}_{\mathrm{MgH}}^{\mathrm{f}}\right)+\left(\mu_{\mathrm{H} 0}^{\mathrm{vib}}-\mu_{\mathrm{MgH}}^{\mathrm{vib}}\right) \\
& +k T \ln \left(\frac{\mathrm{Z}_{\mathrm{MgH}}^{\mathrm{cfg}}}{\mathrm{Z}_{\mathrm{H} 0}^{\mathrm{cfg}}}\right)+k T \ln \left(\frac{\mathrm{Z}_{\mathrm{MgH}}^{\mathrm{spn}}}{\mathrm{Z}_{\mathrm{H} 0}^{\mathrm{spn}} \mathrm{Z}_{\mathrm{Mg} 0}^{\mathrm{spn}}}\right)
\end{aligned}
$$

where $[\mathrm{N}]=4.37 \times 10^{22}$ atoms $/ \mathrm{cm}^{3}$ is the atomic density of nitrogen, $Z_{\mathrm{MgH}}^{\mathrm{cfg}}=3$ is the number of equivalent configurations per $\mathrm{Mg}$ atom, $Z_{\mathrm{MgH}}^{\mathrm{spn}}=1$, and $\mathrm{Z}_{\mathrm{Mg} 0}^{\mathrm{spn}}=2$. The equation for $[\mathrm{SiH}]$ is analogous, with $Z_{\mathrm{SiH}}^{\mathrm{cfg}}=3, Z_{\mathrm{SiH}}^{\mathrm{spn}}=1$, and $Z_{\mathrm{Si} 0}^{\mathrm{spn}}=2$. Finally, from the reaction $\mathrm{H}^{0} \div \mathrm{H}^{0} \leftrightarrow \mathrm{H}_{2}$,

$$
k \ln \left(\frac{[\mathrm{H} 2][\mathrm{N}]}{\left[\mathrm{H}^{0}\right]\left[\mathrm{H}^{0}\right]}\right)=\left(2 \mathrm{E}_{\mathrm{H} 0}^{\mathrm{f}}-2 \mathrm{E}_{\mathrm{H} 2}^{\mathrm{f}}\right)+\left(2 \mu_{\mathrm{H} 0}^{\mathrm{vib}}-\mu_{\mathrm{H} 2}^{\mathrm{vib}}\right)+\mathrm{kT} \ln \left(\frac{\mathrm{Z}_{\mathrm{H} 2}^{\mathrm{spn}}}{\mathrm{Z}_{\mathrm{H} 0}^{\mathrm{spn}} \mathrm{Z}_{\mathrm{H} 0}^{\mathrm{spn}}}\right)
$$

where the configurational-degeneracy term is zero, and $\mathrm{Z}_{\mathrm{H} 2}^{\mathrm{spn}}=1$.

Equations (3)-(7) determine the equilibrium populations of the $\mathrm{H}$ states for given values of total $\mathrm{H}$ density $[\mathrm{H}], \mathrm{E}_{\mathrm{F}},\left[\mathrm{Mg}^{0}\right]$, and $\left[\mathrm{Si}^{0}\right]$. In order to evaluate the latter three quantities, we impose overall charge neutrality and make use of the additional equations

$$
k T \ln \left(\frac{\left[\mathrm{Mg}^{-}\right]}{\left[\mathrm{Mg}^{0}\right]}\right)=\left(\mathrm{E}_{\mathrm{F}}-\mathrm{E}_{\mathrm{Mg}-}^{\mathrm{f}, 0}\right)+\mathrm{kT} \ln \left(\frac{\mathrm{Z}_{\mathrm{Mg}-}^{\mathrm{spn}}}{\mathrm{Z}_{\mathrm{Mg} 0}^{\mathrm{spn}}}\right)
$$


with an analogous relation between $\left[\mathrm{Si}^{+}\right]$and $\left[\mathrm{Si}^{0}\right]$,

$$
\left[h^{+}\right]=\int_{E_{V}-l e V}^{E_{V}} N_{v a l}(E) F\left(E_{F}-E\right) d E
$$

and

$$
\left[e^{-}\right]=\int_{E_{c}}^{E_{c}+l e V} N_{c o n}(E) F\left(E-E_{F}\right) d E
$$

where $Z_{\mathrm{Mg}-}^{\mathrm{spn}}=Z_{\mathrm{Si}+}^{\mathrm{Spn}}=1,\left[\mathrm{~h}^{+}\right]$is the hole density, $\mathrm{N}_{\mathrm{val}}$ is the combined valence-band DOS plotted in Fig. 3, $F(E)$ is the Fermi distribution function, $\left[e^{-}\right]$is the electron density, $E_{c}$ is energy of the conduction-band edge, and $\mathrm{N}_{\text {con }}$ is the conduction-band DOS. (Often the spin degeneracy of the neutral acceptor is multiplied by the degeneracy of the valence band to obtain a "groundstate degeneracy factor," e.g., 4 in the case of Si. This is not appropriate here because band degeneracies are included in the DOS in Fig. 3.)

We turn now to the equilibrium between $\mathrm{H}$ in $\mathrm{GaN}$ and external $\mathrm{H}_{2}$ gas. The chemical potential per $\mathrm{H}$ atom of the gas, expressed in terms compatible with the preceding development, is given by

$$
\mu_{\text {gas }}\left(\mathrm{P}^{*}, \mathrm{~T}\right)=\mathrm{E}_{\text {gas }}^{\mathrm{f}}+\left(\mu_{\text {gas }}\left(\mathrm{P}_{0}^{*}, \mathrm{~T}\right)-\mu_{\text {gas }}\left(\mathrm{P}_{0}^{*}, 0\right)\right)+\frac{1}{2} \mathrm{kT} \ln \left(\frac{\mathrm{P}^{*}}{\mathrm{P}_{0}^{*}}\right)
$$

where $\mathrm{P} *$ is the fugacity (equal to pressure at low pressures) of the gas, $\mathrm{E}_{\text {gas }}^{\mathrm{f}}=-2.24 \mathrm{eV}$ is the zero-temperature formation energy per atom relative to the neutral atom in vacuum, and $\mathrm{P}_{0}^{*}=1$ bar is standard pressure. The quantity $\left(\mu_{\text {gas }}\left(\mathrm{P}_{0}^{*}, \mathrm{~T}\right)-\mu_{\text {gas }}\left(\mathrm{P}_{0}^{*}, 0\right)\right)$ is extracted from published thermodynamic tables 17 and is plotted as a function of temperature in Fig. 5. The solubility of any of the previously discussed $\mathrm{H}$ species in $\mathrm{GaN}$ can be calculated by equating its chemical potential to that of the gas. As a matter of mathematical convenience, we do this for the neutral and always dilute solute $\mathrm{H}^{0}$, thereby avoiding a Fermi-level dependence and saturation effects. The resulting theoretical solubility, $\left[\mathrm{H}^{0}\right]^{\text {sol }}$,is given by 


$$
\begin{aligned}
\mathrm{kT} \ln \left(\frac{\left[\mathrm{H}^{0}\right]^{\mathrm{sol}}}{[\mathrm{N}]}\right) & =\left(\mathrm{E}_{\mathrm{gas}}^{\mathrm{f}}-\mathrm{E}_{\mathrm{H} 0}^{\mathrm{f}}\right)+\left(\mu_{\text {gas }}\left(\mathrm{P}_{0}^{*}, \mathrm{~T}\right)-\mu_{\text {gas }}\left(\mathrm{P}_{0}^{*}, 0\right)\right) . \\
& -\left(\mu_{\mathrm{H} 0}^{\mathrm{vib}}-\mathrm{kT} \ln \left(\mathrm{Z}_{\mathrm{H} 0}^{\mathrm{spn}}\right)\right)+\frac{1}{2} \mathrm{kT} \ln \left(\frac{\mathrm{P}^{*}}{\mathrm{P}_{0}^{*}}\right)
\end{aligned}
$$

We elect to approximate Eq. (12) in terms of a single solubility activation energy and constant prefactor. To this end, the theoretically calculated quantity $\left.\left(\mu_{\mathrm{H} 0}^{\mathrm{vib}}-\mathrm{kT} \ln \left(\mathrm{Z}_{\mathrm{H} 0}^{\mathrm{spn}}\right)\right)\right)_{*}$ is plotted in Fig. 5, along with the difference $\left(\mu_{\mathrm{H} 0}^{\mathrm{vib}}-\mathrm{kT} \ln \left(\mathrm{Z}_{\mathrm{H} 0}^{\mathrm{spn}}\right)\right)-\left(\mu_{\text {gas }}\left(\mathrm{P}_{0}^{*}, \mathrm{~T}\right)-\mu_{\text {gas }}\left(\mathrm{P}_{0}^{*}, 0\right)\right)$ appearing in Eq. (12). This difference is seen to vary approximately linearly with temperature. Using the straight-line fit in the figure, and employing parameter values already discussed, we obtain from Eq. (12)

$$
\left[\mathrm{H}^{0}\right]^{\mathrm{sol}}=\left(6.6 \times 10^{19} \text { atoms } / \mathrm{cm}^{3}\right)\left(\frac{\mathrm{P}^{*}}{\mathrm{P}_{0}^{*}}\right)^{1 / 2} \exp \left(-\frac{2.70 \mathrm{eV}}{\mathrm{kT}}\right) .
$$

The solubilities of all other species can be calculated from $\left[\mathrm{H}^{0}\right]^{\text {sol }}$ using Eqs. (3)-(10).

The theoretically predicted populations of $\mathrm{H}$ states in p-type, $\mathrm{Mg}$-doped GaN are plotted in Fig. 6 as a function of $\left[\mathrm{H}^{0}\right]$, a convenient independent variable because its logarithm varies linearly with $\mathrm{H}$ chemical potential over the entire range. The temperature of the calculation is $700^{\circ} \mathrm{C}$ and the concentration of $\mathrm{Mg}$ acceptors $2 \times 10^{19}$ atoms $/ \mathrm{cm}^{3}$, typical of MOCVD material and post-growth processing. The upper horizontal scale gives the fugacity of $\mathrm{H}_{2}$ gas in equilibrium with the semiconductor. This scale is obtained from Eq. (13) with a modified activation energy, $2.48 \mathrm{eV}$ rather than $2.70 \mathrm{eV}$, chosen to produce agreement with solubility data for p-type material discussed in Section IV. Similar graphs for intrinsic GaN and for n-type, Si-doped material with a dopant concentration of $2 \times 10^{19}$ atoms $/ \mathrm{cm}^{3}$ appear in Figs. 7 and 8 . 
Figure 6 shows a substantial solubility of $\mathrm{H}$ in $\mathrm{Mg}$-doped $\mathrm{GaN}$ for $\mathrm{H}_{2}$ pressures extending well below 1 bar. There is a pronounced saturation when $\left[\mathrm{H}^{+}\right]+[\mathrm{MgH}]$ approaches the total $\mathrm{Mg}$ concentration $[\mathrm{Mg}]$, corresponding to complete compensation and passivation of the acceptor; further additions of $\mathrm{H}$ are inhibited by a rapid rise in Fermi level that increases the energy of the $\mathrm{H}^{+}$state as shown in Fig. 2. The concentrations of $\mathrm{H}^{+}$and $\mathrm{MgH}$ are predicted to be comparable at $700^{\circ} \mathrm{C}$, with the greater number of lattice sites for the first state counterbalancing the lower formation energy of the second. This contrasts with the situation at room temperature, where virtually all of the $\mathrm{H}$ is predicted to occupy the $\mathrm{Mg}-\mathrm{H}$ complex.

The above saturation persists to a $\mathrm{H}_{2}$-gas fugacity of $\sim 1012$ bar, beyond which interstitial $\mathrm{H}_{2}$ is predicted to be the dominant constituent of solution. At such high fugacities, where the gas equation of state is far from ideal, $\mathrm{P}^{*}$ is much greater than the pressure, $\mathrm{P}$; using the equation of state, 28 one finds that $\mathrm{P}^{*}=10^{12}$ bar corresponds to $\mathrm{P}=1.6 \times 10^{5}$ bar. We consider it an open question whether, at such high chemical potentials and pressures, interstitial $\mathrm{H}_{2}$ is stable against formation of $\mathrm{H}_{2}$ gas bubbles, which is seen in GaN ion-implanted with $\mathrm{H}^{29}$ As the $\mathrm{H}$ chemical potential rises still further in the model system, $\mathrm{H}^{+}$and $\mathrm{H}^{-}$ultimately approach equal concentrations and become the dominant charged species in the system. We believe, however, that experimental realization of this situation in highly-doped p-type material is unlikely because of the extreme $\mathrm{H}$ chemical potential required.

The predicted behavior of $\mathrm{H}$ in intrinsic $\mathrm{GaN}$ is qualitatively different from that in p-type material, as seen in Fig. 7. The solubility at lower pressures is greatly reduced, and the near equality of the $\mathrm{H}^{+}$and $\mathrm{H}^{-}$concentrations develops at a $\mathrm{H}_{2}$-gas pressure of only $\sim 1$ bar. Under this condition the material is slightly n-type. A further large change occurs on going to heavily Si-doped, n-type GaN. The modeled behavior is analogous to that for the p-type case, with significant solubility at 1 bar gas pressure and saturation when $\left[\mathrm{H}^{-}\right]$approaches the donor concentration; however, the pressure required for saturation is shifted upward from p-type, primarily due to the higher formation energies of $\mathrm{H}^{-}$and $\mathrm{SiH}$ shown in Fig. 2. 


\section{EXPERIMENTS AND COMPARISON WITH THEORY}

Gallium nitride was grown epitaxially on sapphire by MOCVD as described elsewhere. 30 The films were 1.5-2 $\mu \mathrm{m}$ thick, and included an intermediate layer of higher defect density and nonuniform doping extending $\sim 0.2-0.4 \mu \mathrm{m}$ from the substrate interface. Oxygen and $\mathrm{C}$ impurities were present at a concentration of $\sim 10^{17}$ atoms $/ \mathrm{cm}^{3}$ after growth. The p-type material was doped with $\mathrm{Mg}$ to a concentration of approximately $5 \times 10^{19} \mathrm{atoms} / \mathrm{cm}^{3}$, and typically exhibited a room-temperature hole concentration near $4 \times 10^{17} \mathrm{~cm}^{-3}$ after $\mathrm{H}$ outgassing, as determined by Hall-effect measurements. Representative depth profiles of the $\mathrm{Mg}, \mathrm{C}$, and $\mathrm{O}$ obtained by secondary-ion mass spectrometry (SIMS) 31 are shown in Fig. 9, with the concentration scales being based upon ion-implanted standards. Nominally undoped material was in fact n-type, as is generally found for MOCVD GaN, with a typical room-temperature carrier concentration of $1 \times 10^{17} \mathrm{~cm}^{-3}$; we provisionally assume that the principal donor is $O$ on the basis of prior experimental and theoretical studies. ${ }^{32,33}$ At the beginning of the experiments, the grown-in $\mathrm{H}$ was outgassed by vacuum annealing. This usually entailed 1 hour at $900^{\circ} \mathrm{C}$, which in the case of the p-type material reduced the $\mathrm{H}$ concentration to $\sim 10^{17}$ atoms $/ \mathrm{cm}^{3}$; in one instance, however, the anneal was 1 hour at $800^{\circ} \mathrm{C}$, resulting in a concentration of $\sim 10^{18} \mathrm{H} / \mathrm{cm}^{3}$ as found from SIMS. The annealing was carried out in a quartz furnace tube that was continuously ion-pumped to a pressure of $\sim 10^{-7}$ Torr.

The behavior of $\mathrm{H}$ in $\mathrm{GaN}$ was investigated using the deuterium (D) isotope. This was introduced by heating in $\mathrm{D}_{2}$ gas at pressures from 0.0013 to 0.88 bar and temperatures from 600 to $800^{\circ} \mathrm{C}$. These treatments were carried out in the aforementioned furnace tube, which was pumped to high vacuum and then charged with research-grade gas. Charging was terminated by removing the furnace in $\sim 1 \mathrm{~s}$ while the gas remained in the tube. The $\mathrm{D}$ concentration was determined primarily through the nuclear reaction $\mathrm{D}\left({ }^{3} \mathrm{He}, \mathrm{p}\right){ }^{4} \mathrm{He}$, which was produced by a ${ }^{3} \mathrm{He}$ ion beam. Protons from the reaction were counted as a function of ${ }^{3} \mathrm{He}$ energy from 0.4 to 1.6 $\mathrm{MeV}$, and the concentration-versus-depth profile of the $\mathrm{D}$ was then extracted by a deconvolution procedure 34 using the published energy-dependent nuclear cross section 35 and He-ion slowing 
rate. 36 This approach determines the absolute concentration without using reference standards, and the estimated uncertainty is $\pm 15 \%$ under the conditions of the present experiments. In comparison, the concentrations obtained from SIMS are considered to be accurate within about a factor of 1.5; SIMS was nevertheless employed to profile $D$ in selected cases because of its higher depth resolution and greater sensitivity. An example of nuclear-reaction profiling is given in Fig. 10, which shows the measured nuclear-reaction yield and derived concentration profile for a Mg-doped specimen that was charged in $\mathrm{D}_{2}$ gas at 0.88 bar and $700^{\circ} \mathrm{C}$ for 5 hours. In carrying out the deconvolution, the concentration profile is approximated by a small number of contiguous straight-line segments whose positions along the depth axis are chosen to accommodate known transitional regions such as the surface and the base of the $\mathrm{Mg}$-doped region. The termini of these segments are then adjusted in concentration to fit the measured nuclear-reaction yields in a least-squares sense. The fit to the data is represented by the curve in the figure.

The equilibrium concentration of $\mathrm{D}$ in $\mathrm{Mg}$-doped $\mathrm{GaN}$ exposed to $\mathrm{D}_{2}$ gas at $700^{\circ} \mathrm{C}$ was measured as a function of $D_{2}$ pressure, and the results are shown in Fig. 11. The sequence of the charging pressures is indicated by the numbers adjacent to the data points, and was chosen so as to establish reversibility. Data point number 2 is from the depth profile in Fig. 10. Measurement number 4 followed a vacuum anneal that produced a concentration below the range plotted. The uptake and release of $\mathrm{D}$ are retarded by a surface barrier, whose properties will be discussed in a subsequent paper. Consequently, in order to confirm the attainment of equilibrium, multiple measurements for different anneal times were carried out at a given pressure. Uptake rate increases with increasing pressure, so that the longest anneal was at the lowest pressure, 64 hours at 0.0013 bar. For all of the experiments discussed herein, diffusion within the GaN film is not expected to be rate-controlling. This is inferred by using the diffusion activation energies in Table I and a representative prefactor of $10^{-3} \mathrm{~cm}^{2} / \mathrm{s}$.

The saturation concentration of D in Fig. 11 is near $2.0 \times 10^{19} \mathrm{atoms} / \mathrm{cm}^{3}$, significantly less than the $\mathrm{Mg}$ concentration of $\sim 5 \times 10^{19}$. This difference was observed for materials from a 
number of growth runs, with saturation levels ranging from 1.9 to $2.5 \times 10^{19} \mathrm{D} / \mathrm{cm}^{3}$. Such behavior is not unexpected, since room-temperature hole concentrations in Mg-doped MOCVD $\mathrm{GaN}$ are generally found to be less than predicted for fully active, uncompensated $\mathrm{Mg}$ acceptors. As already noted, the specimens used in the present study exhibited room-temperature hole concentrations near $4 \times 10^{17} \mathrm{~cm}^{-3}$ after $\mathrm{H}$ outgassing, whereas the formalism of Section III predicts that $5 \times 10^{19} \mathrm{Mg} / \mathrm{cm}^{3}$ with no compensation will result in a hole concentration of $2.0 \times 10^{18} \mathrm{~cm}^{-3}$ at $300 \mathrm{~K}$. While the origin of such differences has not been definitively established, possible factors include compensation by donors such as the $\mathrm{N}$ vacancy and electrical inactivity of some of the $\mathrm{Mg}$ atoms. 33 We note also that the saturation concentration of $\mathrm{D}$ did not vary in exact proportion to the $\mathrm{Mg}$ concentration in a given film. This is seen in Fig. 12, which shows SIMS profiles of $\mathrm{Mg}$ and $\mathrm{D}$ and a nuclear-reaction profile of $\mathrm{D}$ after charging at $600^{\circ} \mathrm{C}$. We infer that the aforementioned causes of the reduced $\mathrm{D}$ saturation concentration and reduced room-temperature hole act nonuniformly during growth. In analyzing cases like that of Fig. 12, we take the D concentration to be the average over the central, relatively flat region of the nuclear-reaction profile.

In modeling the behavior of the $\mathrm{D}$ in our p-type material, we assume the presence of fully ionized compensating donors in addition to the $\mathrm{Mg}$ acceptors, and we adjust the concentrations $[\mathrm{Mg}]$ and [donor] to reproduce both the saturation $\mathrm{D}$ concentration observed at elevated temperatures and the measured room-temperature hole concentration of $\sim 4 \times 10^{17} \mathrm{~cm}^{-3}$. In the case of the specimen of Fig. 11 , this yields $[\mathrm{Mg}]=2.4 \times 10^{19} \mathrm{atoms} / \mathrm{cm}^{3}$ and $[\mathrm{donor}]=0.4 \times 10^{19}$ $\mathrm{cm}^{-3}$. A noteworthy feature of the predicted behavior is that the saturation concentration of $D$ is nearly equal to the difference $[\mathrm{Mg}]$ - [donor]. Other parameter values are as discussed in Sections II and III, except that the vibrational frequencies are divided by $\sqrt{ } 2$ to reflect the mass of the $\mathrm{D}$ isotope, and the chemical potential of $\mathrm{H}_{2}$ gas in Fig. 5 is replaced by the slightly different potential for $\mathrm{D}_{2}$ gas; 17 these changes give the slightly different solubility relation

$$
\left[\mathrm{D}^{0}\right]^{\mathrm{sol}}=\left(6.2 \times 10^{19} \text { atoms } / \mathrm{cm}^{3}\right)\left(\frac{\mathrm{P}^{*}}{\mathrm{P}_{0}^{*}}\right)^{1 / 2} \exp \left(-\frac{2.72 \mathrm{eV}}{\mathrm{kT}}\right) \text {. }
$$


The pressure-dependent solubility obtained from the theoretical model is given by the solid curve in Fig. 11. The experimental data lie above the prediction, implying that the absolute $\mathrm{H}$ energies in GaN obtained from density-functional theory err in the positive direction. The dashed curve shows the result when all of the formation energies for interstitial $\mathrm{H}$ in Fig. 2 are reduced by $0.22 \mathrm{eV}$, which is accomplished by changing the activation energy in Eq. (14) to $2.50 \mathrm{eV}$. In view of the fact that the solubility comparison tests absolute formation energies, we regard the above disparity as within the theoretical uncertainty. As already noted, the fugacity scales in Figs. 6-8 were calculated using the same reduction of the activation energy in Eq. (13).

The gas-phase charging experiments on p-type material were also carried out at 600 and $800^{\circ} \mathrm{C}$. The equilibrium concentration reached at a pressure of 0.88 bar was not resolvably different between 600 and $700^{\circ} \mathrm{C}$, in accord with the expected attainment of near saturation at $[D]=[\mathrm{Mg}]-[$ donor $]$ for both temperatures. Examination of the pressure regime below saturation was not feasible at $600^{\circ} \mathrm{C}$ because of the slow uptake at such low pressures. In the case of $800^{\circ} \mathrm{C}$, the higher $\mathrm{D}_{2}$ pressures caused erosion of the GaN films as observed by both SIMS and Rutherford backscattering spectrometry, and this prevented measurements over the full range of pressures. Such $\mathrm{H}$-accelerated decomposition has been reported previously. 37 We nevertheless achieved a concentration measurement for 0.0013 bar, and by observing saturation at lower temperatures in the same material, we determined that the solubility was reduced to approximately $36 \%$ of the saturation level; in comparison, the value predicted theoretically using the modified form of Eq. (14) is $25 \%$.

The states of grown-in $\mathrm{H}$ and gas-phase-charged $\mathrm{D}$ were examined by infrared (IR) vibrational spectroscopy. In all cases we, observed only the absorptions previously identified with the $\mathrm{Mg}-\mathrm{H}$ and $\mathrm{Mg}-\mathrm{D}$ complexes. ${ }^{12}$ This is consistent with our theoretical model, which predicts that, at room temperature, virtually all of the $\mathrm{H}$ and $\mathrm{D}$ should occupy the acceptor complex. The IR spectral peaks measured for our specimens are shown in Fig. 13, where they are compared with the theoretical stretch-mode frequency for the $\mathrm{Mg}-\mathrm{H}$ complex given in Table I. The latter comparison provides another test of density-functional theory, and the 
disparity of $5 \%$ is considered within the theoretical uncertainty. As a further test for $D$ in other states, we compared the strength of the IR absorption with total $D$ content as measured by nuclear-reaction analysis during isothermal release at $700^{\circ} \mathrm{C}$, and the results are shown in Fig. 14. Although the determination of the IR absorption strength is somewhat imprecise, the similarity of the two variations tends further to support the predominance of a single $D$ state after the gasphase charging.

The above gas-phase charging is predicted to reduce the hole concentration greatly as a result of compensation and $\mathrm{MgH}$ formation, as seen in Fig. 6. To verify this, we made roomtemperature resistivity and hall-effect measurements before and after the introduction of $\mathrm{D}$. The Mg-doped specimen was initially activated by rapid thermal annealing at $1000^{\circ} \mathrm{C}$ for $7 \mathrm{~s}$ in flowing $\mathrm{N}_{2}$. Contacts for the four-point electrical measurements were subsequently made by electron-beam deposition of $\mathrm{Ni}$ and then Au. Before D charging, the resistivity of the film was $2.6 \Omega$-cm and the carrier concentration $3.6 \times 10^{17} \mathrm{~cm}^{-3}$. After heating in $\mathrm{D}_{2}$ gas at $700^{\circ} \mathrm{C}$ for 4 hours, the resistivity had increased to $1.4 \times 10^{4} \Omega-\mathrm{cm}$. While the hole concentration could not be determined quantitatively at such high resistivities, it was also reduced by several orders of magnitude from the starting value.

In experiments reported elsewhere, $38 \mathrm{Mg}$-doped $\mathrm{GaN}$ was $\mathrm{D}$-charged in an electroncyclotron-resonance $\mathrm{D}_{2}$ plasma at $600^{\circ} \mathrm{C}$. The very high $\mathrm{D}$ chemical potential arising from athermal injection at $\sim 30 \mathrm{eV}$ produced concentrations as high as $2 \times 10^{20} \mathrm{D} / \mathrm{cm}^{3}$, or $\sim 4$ times the $\mathrm{Mg}$ concentration, throughout the $\mathrm{Mg}$-doped region of the film. During annealing at $700^{\circ} \mathrm{C}$, this excess D was released much more rapidly than shown in Fig. 14, and comparisons between nuclear-reaction analysis and IR spectroscopy indicated that the associated D state is not IR active. Further experiments are in progress to determine whether interstitial $D_{2}$ having the configuration of Fig. 1(g) constitutes a significant part of the excess.

We also carried out $\mathrm{D}_{2}$-gas exposures of $\mathrm{GaN}$ that was nominally undoped but in fact $\mathrm{n}$-type, presumably due to the presence of O-impurity donors. 32,33 This interpretation of the doping in our material is consistent with the near equality of the grown-in O concentration 
measured by SIMS and the corresponding carrier concentration from Hall-effect measurements, both $\sim 10^{17} \mathrm{~cm}^{-3}$. The specimen was outgassed in high vacuum at $900^{\circ} \mathrm{C}$ for 1 hour and then charged in $\mathrm{D}_{2}$ gas at 0.88 bar and $700^{\circ} \mathrm{C}$ for 4 hours, whereupon $\mathrm{D}, \mathrm{O}$, and $\mathrm{C}$ were depth-profiled by SIMS. The resulting profiles are shown in Fig. 15, where an approximately uniform D concentration is seen in the central region of the film. The two anneals also increased the concentrations of $\mathrm{O}$ and $\mathrm{C}$, to $\sim 10^{18}$ atoms $/ \mathrm{cm}^{3}$. This experimental condition was treated with the theoretical model using Eq. (14) with the reduced solubility activation energy of $2.5 \mathrm{eV}$ deduced from Fig. 11, assuming fully ionized $O$ donors to be present at the measured $O$ concentration of $1.4 \times 10^{18}$ atoms $/ \mathrm{cm}^{3}$, and neglecting pairing reactions between $\mathrm{H}$ and $\mathrm{O}$. The predicted $\mathrm{D}$ concentration is given by the horizontal line in the figure, and it is seen to agree well with the experimental result. While this comparison cannot be taken as entirely definitive because the origin and level of the electronic doping are not known with certainty and the relative small $\mathrm{D}$ concentration admits the possibility of defect-related states being significant, we nevertheless consider the agreement to be further evidence for the applicability of the theoretical model.

\section{CONCLUSIONS AND IMPLICATIONS}

. The equilibrium behavior of $\mathrm{H}$ in $\mathrm{GaN}$ at elevated temperatures was quantitatively predicted using results obtained from density-functional theory, and these predictions were compared with measured solubilities and other experimental information. We consider the consistency between theory and experiment to be satisfactory, in that quantitative agreement for the solubility required an adjustment of only $0.2 \mathrm{eV}$ in the solution-state formation energies, and the predicted $\mathrm{H}$ stretch-mode frequency for the $\mathrm{Mg}-\mathrm{H}$ complex differs from an experimentally observed IR absorption by only 5\%. Thus, recognized $H$ states and physical process appear adequate to account for the equilibrium properties considered here. Moreover, as we shall report separately, a similar conclusion holds for thermal release and uptake from the gas phase, provided that account is taken of a pronounced surface-barrier effect. These considerations 
suggest that a unified, quantitatively predictive model of $\mathrm{H}$ behavior based on first principles may be achievable for temperatures $>400^{\circ} \mathrm{C}$ where rapid local equilibration among the $\mathrm{H}$ states is expected.

\section{ACKNOWLEDGEMENTS}

The calculations based on density-functional theory were carried out using the ab-initio, total-energy and molecular-dynamics package VASP, developed at the Institute für Theoretische Physik of the Technische Universität Wien. This work was supported by the U. S. Department of Energy under Contract DE-AC04-94AL85000, primarily under the auspices of the Office of Basic Energy Sciences. Sandia National Laboratories is a multiprogram laboratory operated by Sandia Corporation, a Lockheed Martin Company, for the United States Department of Energy.

\section{APPENDIX: CONTRIBUTION OF DEGENERACY TO H CHEMICAL POTENTIAL}

Here we discuss further the contributions to $\mathrm{H}$ chemical potential from the multiplicity of available lattice sites and spin degeneracy. Consider a unit volume of $\mathrm{GaN}$ containing $[\mathrm{N}]$ nitrogen atoms, $[\mathrm{H}]$ hydrogen atoms, $\left[\mathrm{H}^{+}(\mathrm{AB})\right]$ positive $\mathrm{H}$ atoms at the $\mathrm{N}$ antibonding site, and so on using the notation of Section III. For the simplified case of no $\mathrm{H}$ binding to dopants, no $\mathrm{H}_{2}$, only one atomic configuration per $\mathrm{N}$ atom for any of the $\mathrm{H}$ states, and no spin degeneracy, elementary consideration of permutations and combinations gives for the number of distinguishable $\mathrm{H}$ states

$$
Z=\frac{[N] !}{\left[\mathrm{H}^{+}(\mathrm{AB})\right] !\left[\mathrm{H}^{+}(\mathrm{BC})\right] !\left[\mathrm{H}^{0}\right] !\left[\mathrm{H}^{-}\right] !([\mathrm{N}]-[\mathrm{H}]) !} .
$$

When $\mathrm{H}$ species $\mathrm{i}$ with total number [i] has more than one atomic configuration per $\mathrm{N}$ atom, $Z_{i}^{\mathrm{cfg}}>1$, the left-hand side of Eq. (AI) is multiplied by $Z_{i}^{\mathrm{cfg}}$ raised to the power [i]. The correction for spin degeneracy, $Z_{i}^{\mathrm{Spn}}$, is analogous. In the event of a pairing reaction with an electrical dopant of concentration $[\mathrm{d}]<<[\mathrm{N}]$ to form a neutral complex denoted $\mathrm{dH}$, the problem 
can be treated by evaluating $\mathrm{Z}$ separately for $\mathrm{H}$ occupying sites unaffected by the dopant and $\mathrm{H}$ occupying dopant binding sites and taking the product of the results. In doing this, account must be taken of the multiple charge states and spin degeneracy of the dopant as well as the H. With these additions one has

$$
\begin{aligned}
& Z=\left(\frac{[\mathrm{N}] !}{\left[\mathrm{H}^{+}(\mathrm{AB})\right] !\left[\mathrm{H}^{+}(\mathrm{BC})\right] !\left[\mathrm{H}^{0}\right] !\left[\mathrm{H}^{-}\right] !\left[\mathrm{H}_{2}\right] !}\right) \\
& \times\left(\frac{\left(\mathrm{Z}_{\mathrm{AB}}^{\mathrm{cfg}}\right)\left[\mathrm{H}^{+}(\mathrm{AB})\right]\left(\mathrm{Z}_{\mathrm{H} 0}^{\mathrm{spn}}\right)\left[\mathrm{H}^{0}\right]}{\left([\mathrm{N}]\left[\mathrm{H}^{+}(\mathrm{AB})\right]-\left[\mathrm{H}^{+}(\mathrm{BC})\right]-\left[\mathrm{H}^{0}\right]-\left[\mathrm{H}^{-}\right]-\left[\mathrm{H}_{2}\right]\right) !}\right) \\
& \times\left(\frac{[\mathrm{d}] !\left(\mathrm{Z}_{\mathrm{dH}}^{\mathrm{cfg}}\right)^{[\mathrm{dH}]}\left(\mathrm{Z}_{\mathrm{d} 0}^{\mathrm{spn}}\right)}{[\mathrm{dH}] !\left[\mathrm{d}^{0}\right] !\left[\mathrm{d}^{+/-}\right] !}\right)
\end{aligned}
$$

where $\mathrm{d}^{0}$ is the neutral dopant, $\mathrm{d}^{+/-}$is its ionized state, factors of type $Z_{i}^{\mathrm{cfg}}$ and $Z_{i}^{\text {spn }}$ have been omitted when equal to 1 , and the reduction in the number of non-pairing $H$ sites due to the presence of the dopant has been neglected. The resulting contribution to the chemical potential of species $i$ is obtained by using the continuum approximation for $\ln (Z)$ based on $\ln (\mathrm{x} !) \cong x \ln (\mathrm{x})-\mathrm{x}$ and taking

$$
\mu_{\mathrm{i}}=-\mathrm{kT} \frac{\partial \ln (\mathrm{Z})}{\partial[\mathrm{i}]}
$$

The equilibrium relations in Section III involve differences between such chemical potentials, and these are algebraically simple when $[\mathrm{H}],[\mathrm{Mg}] \ll[\mathrm{N}]$. For example, the change in the degeneracy-related $\mathrm{H}$ chemical potential arising from the reaction $\mathrm{H}^{0}+\mathrm{Mg}^{0} \rightarrow \mathrm{MgH}$ is 
$-21-$

$$
\begin{aligned}
& \mu_{\mathrm{MgH}}-\mu_{\mathrm{H} 0}-\mu_{\mathrm{Mg} 0}=\mathrm{kT}\left(\ln (\mathrm{MgH})-\ln \left(\mathrm{Z}_{\mathrm{MgH}}^{\mathrm{cfg}}\right)\right) \\
&-\mathrm{kT}\left(\ln \left(\left[\mathrm{H}^{0}\right]\right)-\ln (\mathrm{N})-\ln \left(\mathrm{Z}_{\mathrm{H} 0}^{\mathrm{spn}}\right)\right)-\mathrm{kT}\left(\ln \left(\left[\mathrm{Mg}^{0}\right]\right)-\ln \left(\mathrm{Z}_{\mathrm{Mg} 0}^{\mathrm{spn}}\right)\right)
\end{aligned}
$$

which conforms to Eq. (6) for $\mathrm{Z}_{\mathrm{MgH}}^{\mathrm{spn}}=\mathrm{Z}_{\mathrm{H}}^{\mathrm{cfg}}=1$. 


\section{REFERENCES}

1. S. J. Pearton, J. C. Zolper, R. J. Shul, and F. Ren, J. Appl. Phys. 86, 1 (1999).

2. S. Nakamura, T. Mukai, M. Senow, and N. Iwasa, Jpn. J. Appl. Phys. 31, L139 (1992).

3. C. Yuan, T. Salagaj, A. Gurary, P. Zawadzki, C. S. Chern, W. Kroll, R. A. Stall, Y. Li, M. Schurman, C.-Y. Hwang, W. E. Mayo, Y. Lu, S. J. Pearton, S. Krishnankutty, and R. M. Kolbas, J. Electrochem. Soc., 142, L163 (1995).

4. S. J. Pearton, J. W. Lee, and C. Yuan, Appl. Phys. Lett. 68, 2690 (1996).

5. M. Miyachi, T. Tanaka, Y. Kimura, and H. Ota, Appl. Phys. Lett. 72, 1101 (1998).

6. M. Inamori, H. Sakai, T. Tanaka, H. Amano, and I. Akasaki, Jpn. J. Appl. Phys. 34, 1190 (1995).

7. X. Li and J. J. Coleman, Appl. Phys. Lett. 69, 1605 (1996).

8. J. A. Van Vechten, J. D. Zook, R. D. Horning, and B. Goldenberg, Jap. J. Appl. Phys. 31, 3662 (1992).

9. J. Neugebauer and C. G. Van de Walle, Appl. Phys. Lett. 68, 1829 (1996).

10. J. Neugebauer and C. G. Van de Walle, Phys. Rev. Lett. 75, 4452 (1995).

11. A. F. Wright, Phys. Rev. B 60, R5101 (1999).

12. W. Götz, N. M. Johnson, D. P. Bour, M. D. McCluskey, and E. E. Haller, Appl. Phys. Lett. 69,3725 (1996).

13. S. M. Myers, A. F. Wright, G. A. Petersen, C. H. Seager, M. H. Crawford, W. R. Wampler, and J. Han, MRS Internet J. Nitride Semicond. Res., 2000, accepted.

14. P. Kozodoy, H. Xing, S. P. DenBaars, U. K. Mishra, A. Saxler, R. Perrin, S. Elhamri, and W. C. Mitchel, J. Appl. Phys. 87, 1832 (2000).

15. W. Götz, N. M. Johnson, C. Chen, H. Liu, C. Kuo, and W. Imler, Appl. Phys. Lett. 68, 3144 (1996).

16. J. Jayapalan, B. J. Skromme, R. P. Vaudo, and V. M. Phanse, Appl. Phys. Lett. 73, 1188 (1998).

17. J. Phys. Chem. Ref. Data 14, Suppl. 1, 1985. 
18. A. F. Wright and J. S. Nelson, in Physics and Simulation of Optoelectronic Devices III, edited by M. Osiński and W. W. Chow, (Inter. Soc. for Optical Eng., Proc. Vol. 2399, 1995), pp. 498-514.

19. M. Drechsler, D. M. Hofmann, B. K. Meyer, T. Detchprohm, H. Amano, and I. Akasaki, Jpn. J. Appl. Phys. 34, L1178 (1995).

20. B. K. Meyer, D. Volm, A. Graber, H. C. Alt, T. Detchprohm, A. Amano, and I. Akasaki, Sol. State Commun. 95, 597 (1995).

21. P. Perlin, E. Litwin-Staszewska, B. Suchanek, W. Knap, J. Camassel, T. Suski, R. Piotrzolowski, I. Grzegory, S. Porowski, E. Kaminska, and J. C. Chervin, Appl. Phys. Lett $68,1114(1996)$.

22. S. L. Chuang and C. S. Chang, Appl. Phys. Lett. 68, 1657 (1996).

23. W. W. Chow, A. F. Wright, A. Girndt, F. Jahnke, and S. W. Koch, MRS Symp. Proc. 468, 487 (1997).

24. J. I. Pankove, S. Bloom, and G. Harbeke, RCA Rev. 36, 163 (1975).

25. J. S. Im, A. Moritz, F. Steuber, V. Härle, F. Scholz, and A. Hangleiter, Appl. Phys. Lett. 70, 631 (1997).

26. C. Herring and N. M. Johnson, in Hydrogen in Semiconductors, edited by J. I. Pankove and N. M. Johnson (Academic, New York, 1991), pp. 234-238.

27. T. L. Hill, An Introduction to Statistical Thermodynamics (Dover, New York. 1986), pp. 89-92.

28. H. Hemmes, A. Driessen, and R. Griessen, J. Phys. Chem. C 19, 3571 (1986). P is calculated from $\mathrm{P}^{*}$ using the relation $\mathrm{kT} \ln \left(\mathrm{P}^{*} / \mathrm{P}_{0}^{*}\right)=\int_{\mathrm{P}_{0}}^{\mathrm{P}} \mathrm{v}\left(\mathrm{P}^{\prime}\right) \mathrm{dP}^{\prime}$ where $\mathrm{v}$ is the molecular volume of the gas and $\mathrm{P}_{0}^{*}=\mathrm{P}_{0}=1$ bar .

29. S. M. Myers, J. Han, T. J. Headley, C. R. Hills, G. A. Petersen, C. H. Seager. and W. R. Wampler, Nucl. Instrum. Methods B 148, 386 (1999).

30. J. Han, T.-B. Ng, R. M. Biefield, M. H. Crawford, and D. M. Follstaedt, App. Phys. Lett. 71,3114 (1997). 
31. The SIMS measurements were carried out Charles Evans \& Assoc., Redwood City, California.

32. K. H. Ploog and O. Brandt, J. Vac. Sci. Technol. A 16, 1609 (1998).

33. C. G. Van de Walle, C. Stampfl, and J. Neugebauer, J. Cryst. Growth 189-190, 505 (1998).

34. S. M. Myers, G. R. Caskey, Jr., D. E. Rawl, Jr., and R. D. Sisson, Jr., Metall. Trans. A 14, 2261 (1983).

35. W. Möller and F. Besenbacher, Nucl. Instrum. Meth. 168, 111 (1980).

36. J. F. Ziegler, Helium Stopping Powers and Ranges in All Elemental Matter (Pergamon, New York, 1977).

37. D. D. Koleske, A. E. Wickenden, R. L. Henry, M. E. Twigg, J. C. Culbertson, and R. J. Gorman, Appl. Phys. Lett. 73, 2018 (1998).

38. W. R. Wampler, J. C. Barbour, C. H. Seager, S. M. Myers, A. F. Wright, and J. Han, MRS Internet J. Nitride Semicond. Res., 2000, accepted; and to be published. 
TABLE I. Properties of $\mathrm{H}$ in $\mathrm{GaN}$ at zero temperature from density-functional theory. The formation-energy reference state is the neutral $\mathrm{H}$ atom in vacuum and $\mathrm{GaN}$ with dopants neutral. The vibrational frequencies are divided by the speed of light, $\mathrm{c}$, in accord with general usage.

Species Formation energy at $\mathrm{E}_{\mathrm{F}}=\mathrm{E}_{\mathrm{V}}$ (eV/H atom)

$$
+0.34
$$

$\mathrm{H}^{+}(\mathrm{AB})^{\dagger}$

$\mathrm{H}^{+}(\mathrm{BC}) \ddagger$

$\mathrm{H}^{-}$

$+1.52$

1.6

0.7

0.7

(eV)

0.6

692 (c-axis)

816 ( $\perp$ c-axis, 2 modes)

2970 (stretch)

847 (bend, 2 modes)

$$
3420 \text { (stretch) }
$$

502 (bend. 2 modes)

$\begin{array}{ll}\mathrm{H}^{-} & +1.52 \\ \mathrm{H}_{2} & -1.40\end{array}$

$\mathrm{MgH}$

$-0.7$

3284 (stretch)

Binding energy \#

$(\mathrm{eV})$

$\mathrm{SiH} \quad-0.3$

937 (bend. 2 modes)

1739 (stretch)

$1302,1+27$ (bend)
* For diffusion along the c-axis

$\dagger$ Nitrogen antibonding site $\ddagger$ Bond-center site

\# Relative to ionized dopant and oppositely charged $\mathrm{H}$ 


\section{FIGURE CAPTIONS}

1. Minimum-energy configurations of $\mathrm{H}$ in wurtzite $\mathrm{GaN}$ obtained from density-functional theory. The projection is orthographic, allowing lattice relaxations to be discerned. The energy of $\mathrm{H}^{+}$does not differ significantly between the configurations in (a) and (b).

2. Formation energies for the $\mathrm{H}$ states in Fig. 1 from density-functional theory. The dashed lines for $\mathrm{MgH}$ and $\mathrm{SiH}$ give the formation energy for a reference condition where the electronic dopant is in its lowest-energy state, as opposed to being neutral throughout.

3. Total densities of states for the valence and conduction bands of GaN as obtained from density-functional theory.

4. Contributions to the $\mathrm{H}$ chemical potentials from vibration, evaluated in the harmonic approximation using the theoretical frequencies in Table I.

5. Hydrogen chemical potential of $\mathrm{H}_{2}$ gas at 1-bar pressure evaluated from thermodynamic tables, 17 and the theoretical chemical potential of interstitial $\mathrm{H}^{0}$ arising from vibration and spin degeneracy. The difference between these quantities is approximated by a linear temperature dependence, allowing Eq. (12) to be simplified to Eq. (13).

6. Theoretically predicted concentrations of $\mathrm{H}$ states and carriers in p-type, $\mathrm{Mg}$-doped $\mathrm{GaN}$ at $700^{\circ} \mathrm{C}$ as a function of $\mathrm{H}^{0}$ concentration. The $\mathrm{Mg}$ concentration is $2 \times 10^{19}$ atoms $/ \mathrm{cm}^{3}$. The $\mathrm{H}_{2}$-fugacity scale at the top includes the effect of the $0.22-\mathrm{eV}$ reduction in solution-state energies from theoretical values discussed in the text.

7. Theoretically predicted concentrations of $\mathrm{H}$ states and carriers in intrinsic $\mathrm{GaN}$ at $700^{\circ} \mathrm{C}$ as a function of $\mathrm{H}^{0}$ concentration. The $\mathrm{H}_{2}$-fugacity scale includes the $0.22-\mathrm{eV}$ reduction in solution-state energies from theory discussed in the text.

8. Theoretically predicted concentrations of $\mathrm{H}$ states and carriers in n-type, Si-doped $\mathrm{GaN}$ at $700^{\circ} \mathrm{C}$. The $\mathrm{Si}$ concentration is $2 \times 10^{19}$ atoms $/ \mathrm{cm}^{3}$. The $\mathrm{H}_{2}$-fugacity scale includes the $0.22-\mathrm{eV}$ reduction in solution-state energies from theory discussed in the text.

9. Concentration profiles of $\mathrm{Mg}, \mathrm{C}$, and $\mathrm{O}$ measured by SIMS in as-grown, p-type GaN. 
10. Measured nuclear-reaction yield and derived concentration profile for $\mathrm{D}$ in p-type $\mathrm{GaN}$ after charging in $\mathrm{D}_{2}$ gas at $700^{\circ} \mathrm{C}$. This profile corresponds to data point number 2 in Fig. 11.

11. Experimental and theoretical solubility of D in p-type, $\mathrm{Mg}$-doped $\mathrm{GaN}$ at $700^{\circ} \mathrm{C}$ as a function of $\mathrm{D}_{2}$-gas pressure. The sequence of the experimental measurements is indicated by the numbers, with number 4 corresponding to a vacuum anneal that reduced the pressured below the range plotted. The solid theoretical curve is based on Eq. (14), whereas for the dashed curve the activation energy in Eq. (14) is reduced by $0.22 \mathrm{eV}$.

12. Depth profiles of $\mathrm{Mg}$ and $\mathrm{D}$ in $\mathrm{GaN}$, as obtained from SIMS and nuclear-reaction analysis, after charging in $\mathrm{D}_{2}$ gas at $600^{\circ} \mathrm{C}$.

13. Measured IR absorption peaks from grown-in $\mathrm{H}$ and gas-charged $\mathrm{D}$ in $\mathrm{Mg}$-doped $\mathrm{GaN}$. The $\mathrm{H}$ peak is compared with the theoretically predicted stretch-mode frequency of the $\mathrm{Mg}-\mathrm{H}$ complex.

14. Reduction of the strength of the MgD-related IR absorption during $\mathrm{D}$ thermal release at $700^{\circ} \mathrm{C}$, compared with the reduction of total $\mathrm{D}$ as measured by nuclear-reaction analysis.

15. Concentration profiles of $\mathrm{D}, \mathrm{C}$, and $\mathrm{O}$ in nominally undoped, n-type GaN after charging in $\mathrm{D}_{2}$ gas at $700^{\circ} \mathrm{C}$ and 0.88 bar. The horizontal line gives the predicted $\mathrm{D}$ solubility assuming that all of the $\mathrm{O}$ atoms are ionized donors. 

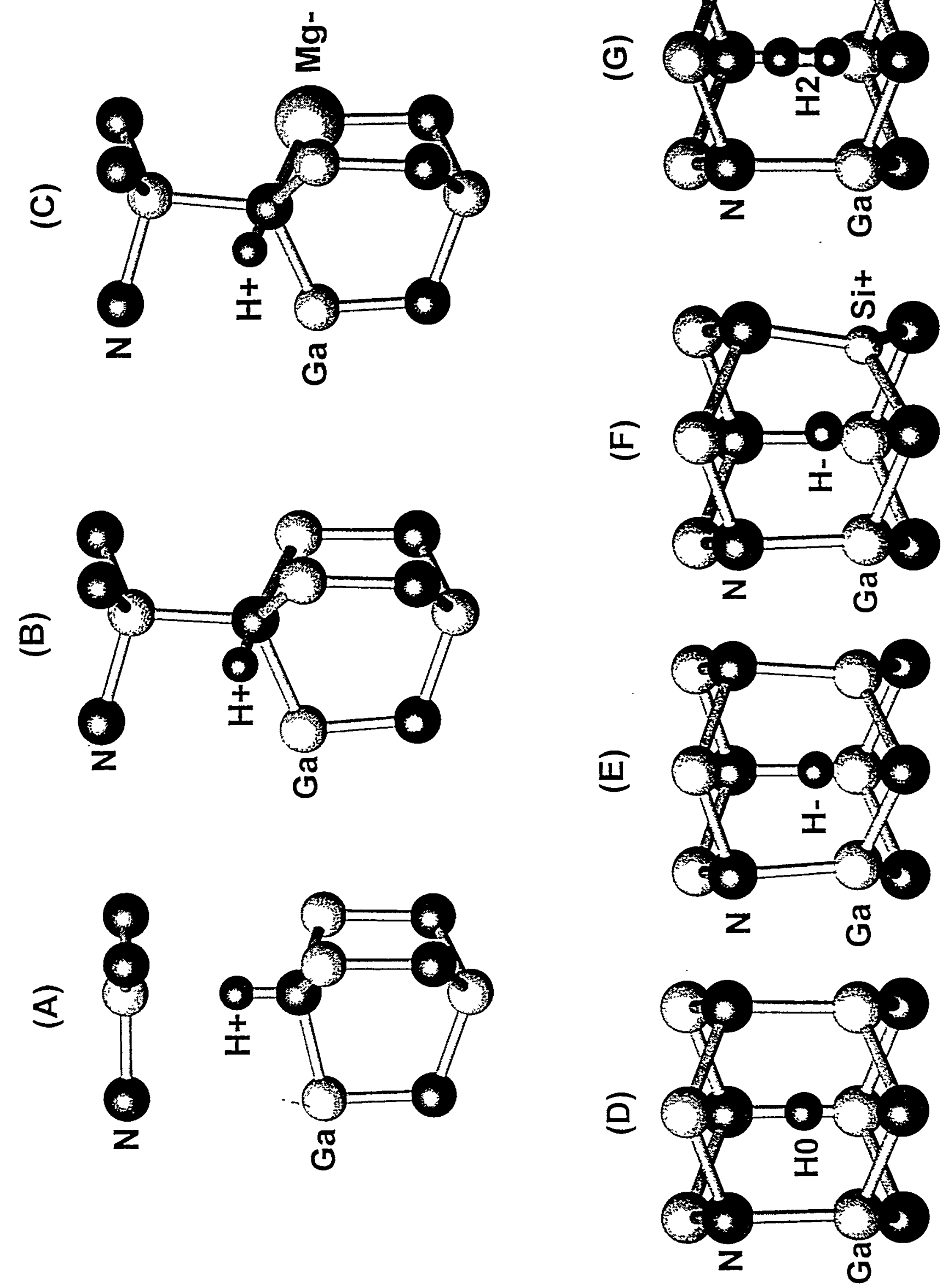


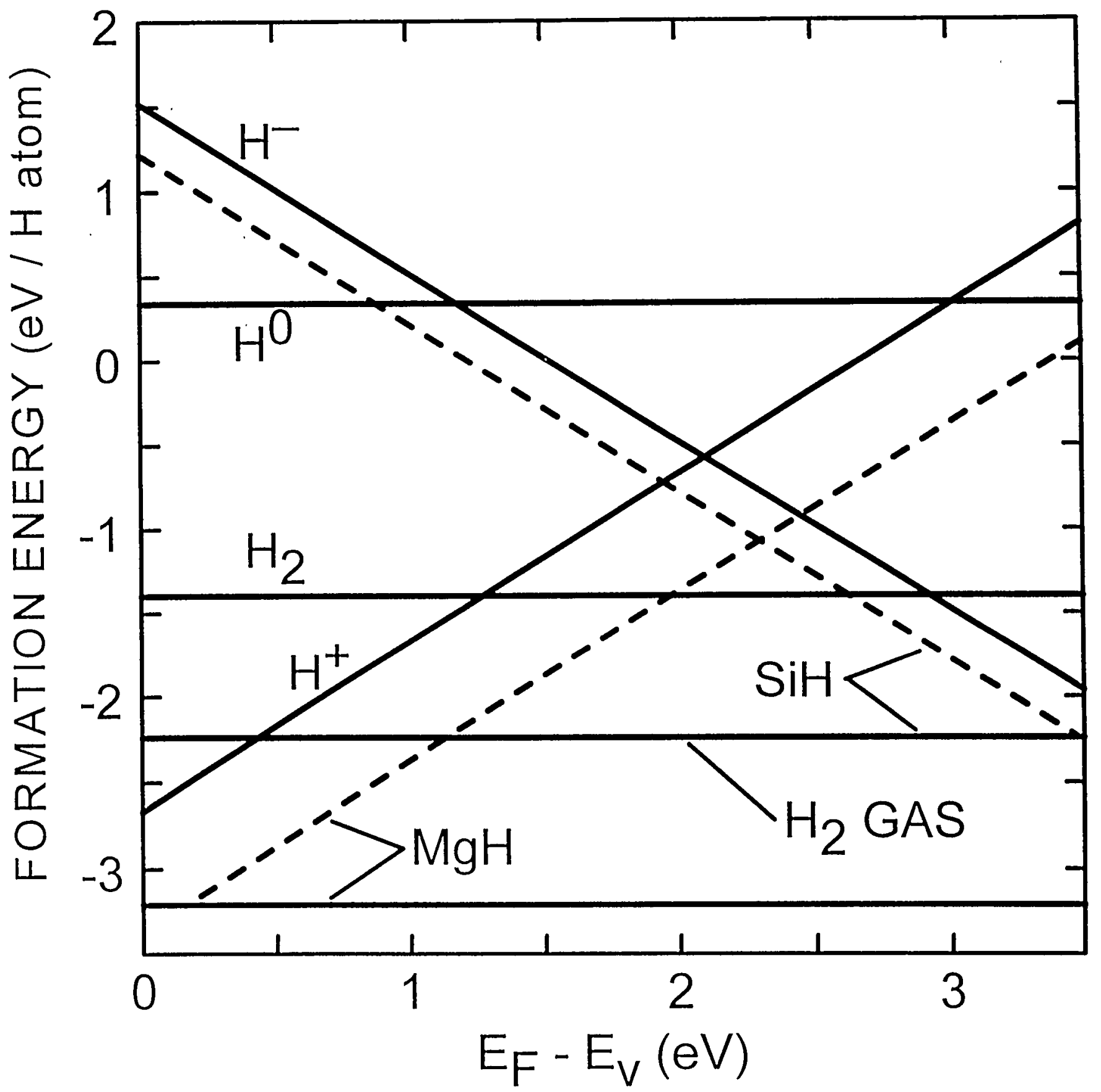




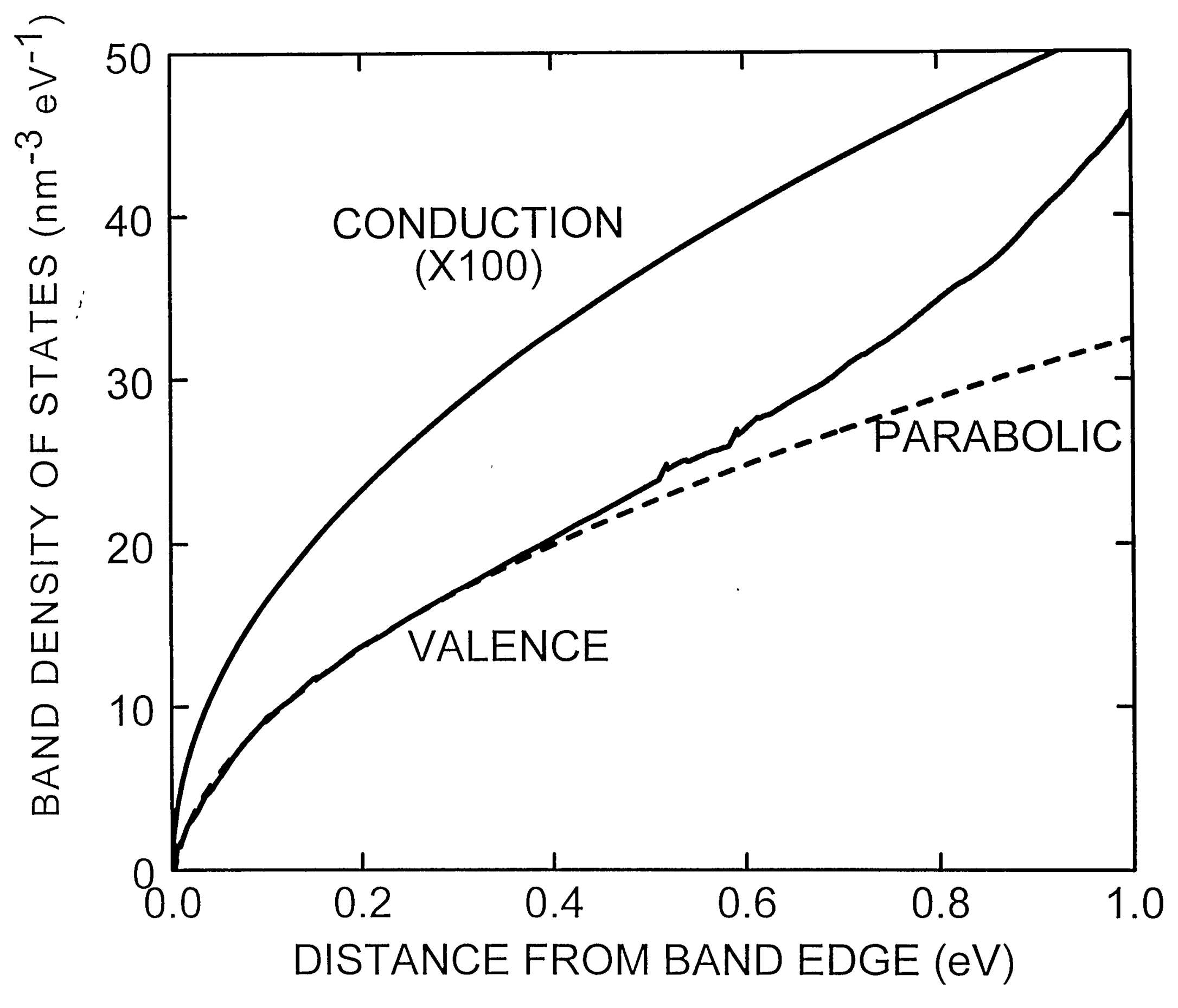




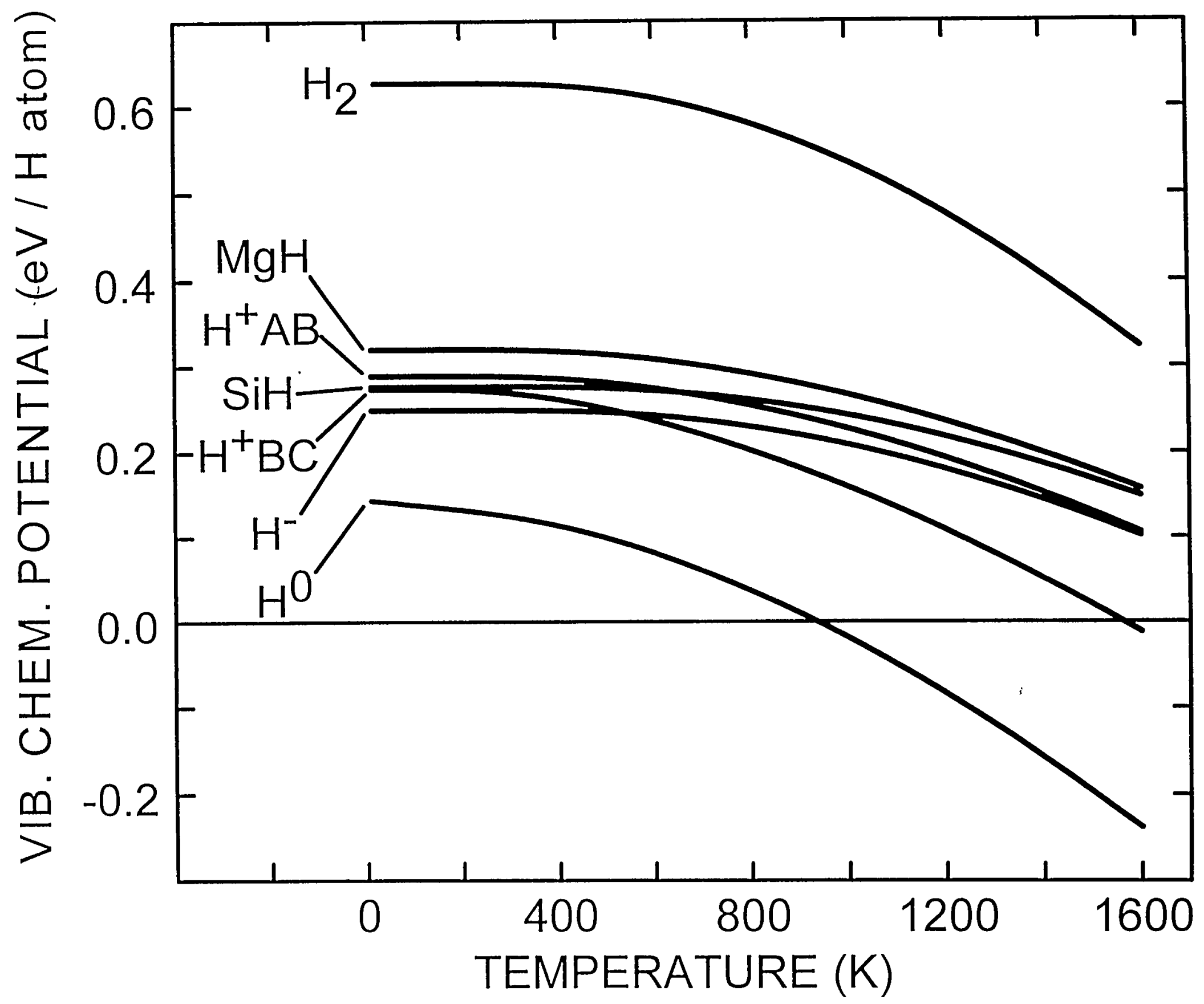




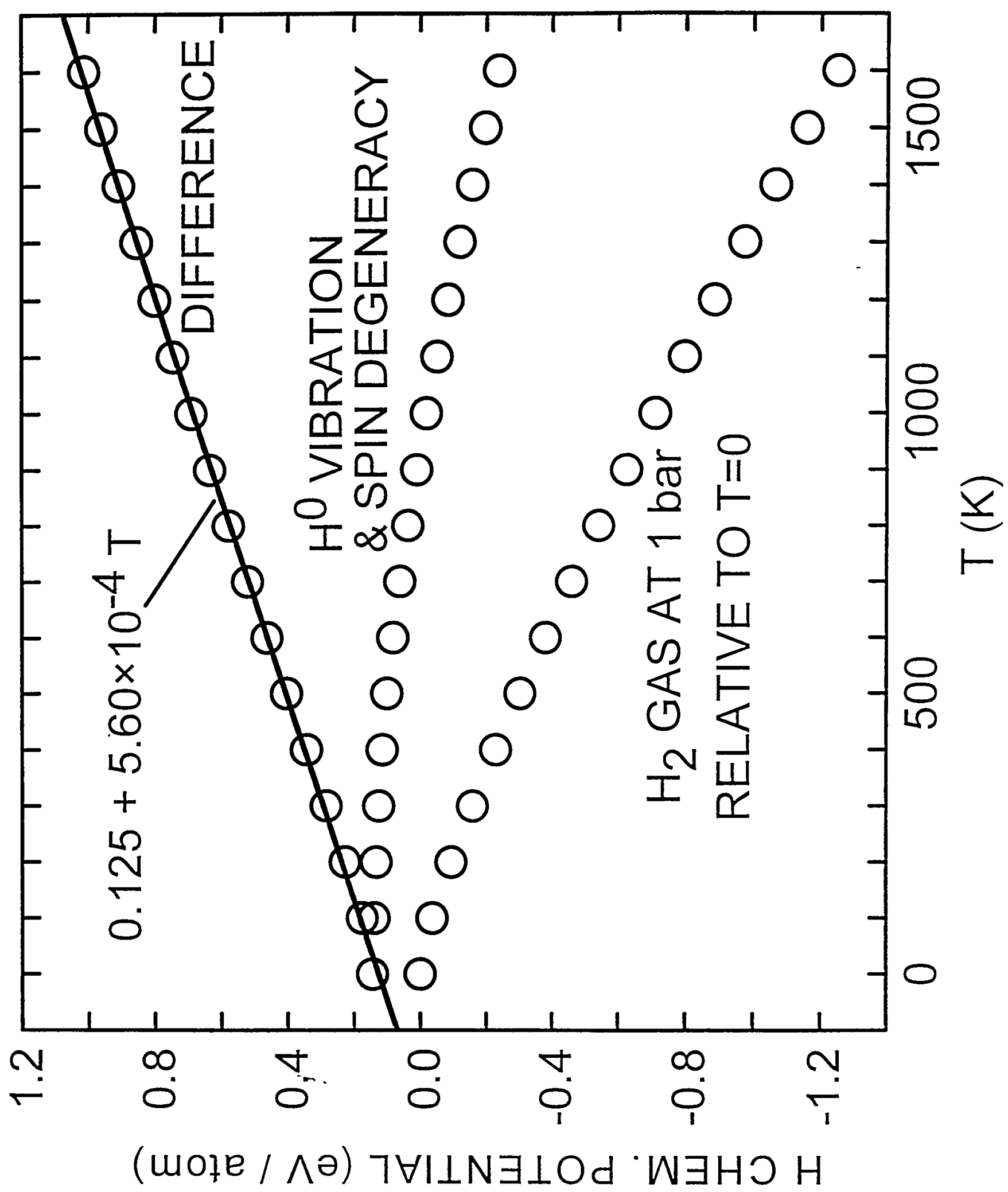


$\mathrm{H}_{2}$ GAS FUGACITY (bar)

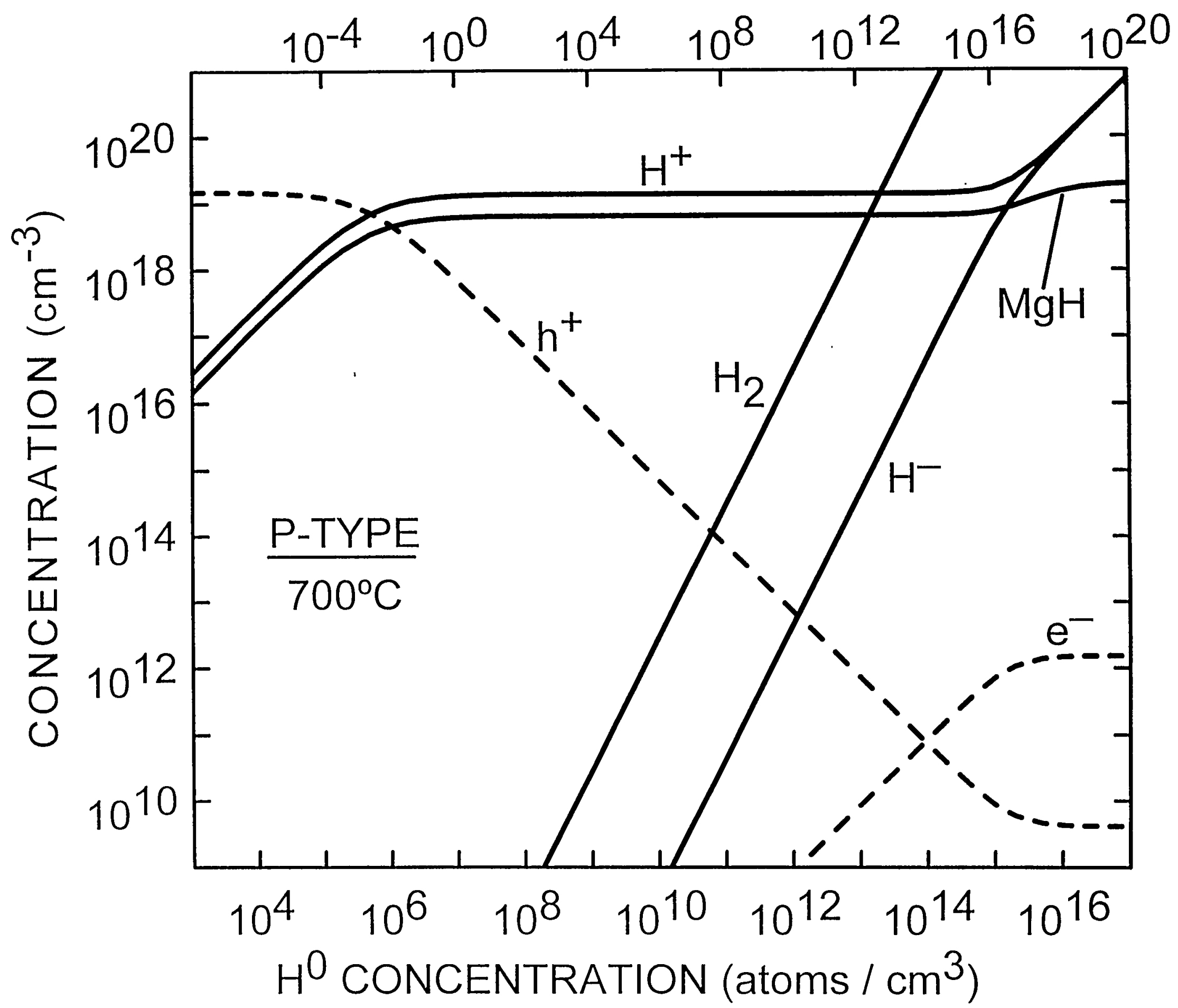


$\mathrm{H}_{2}$ GAS FUGACITY (bar)

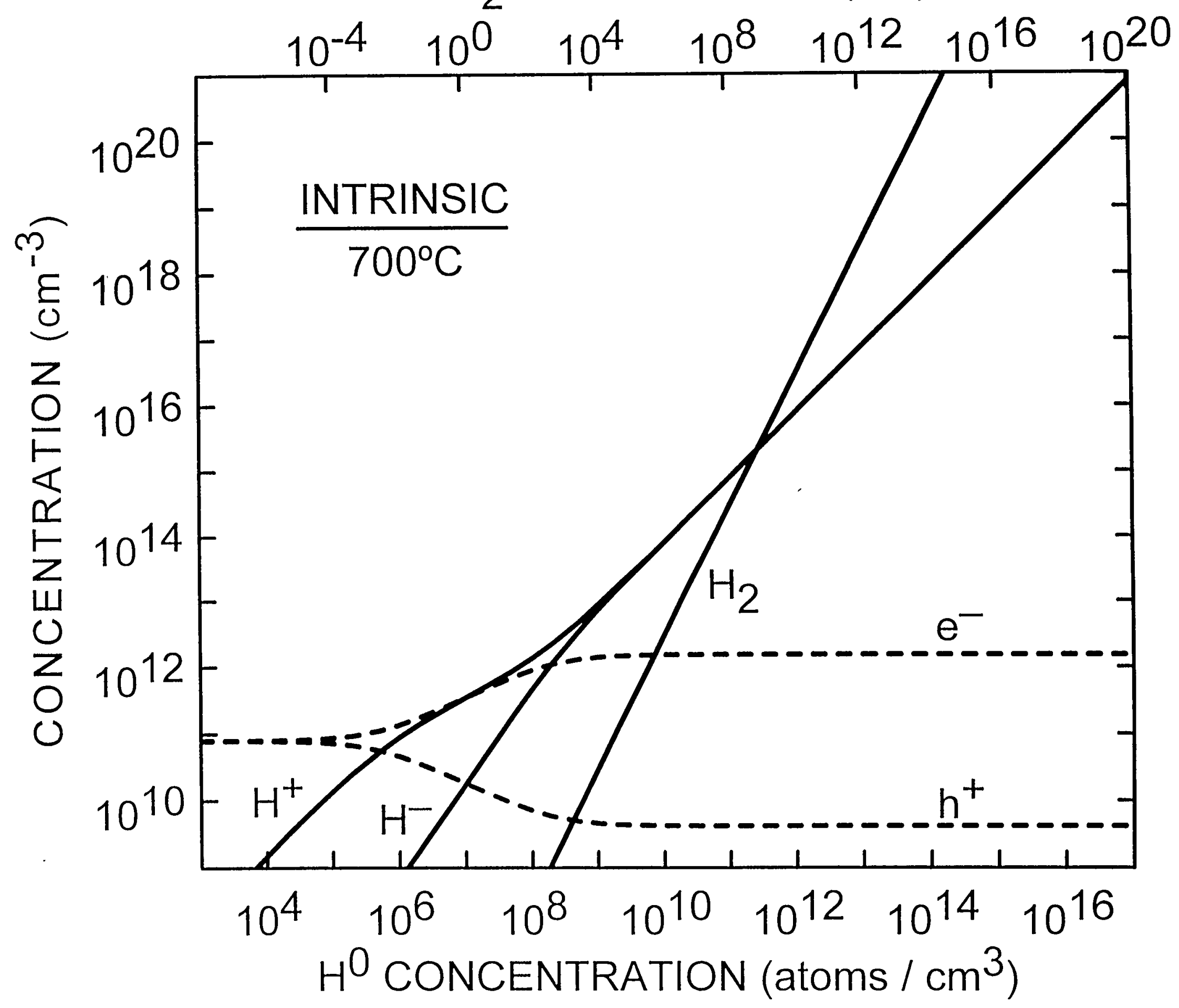




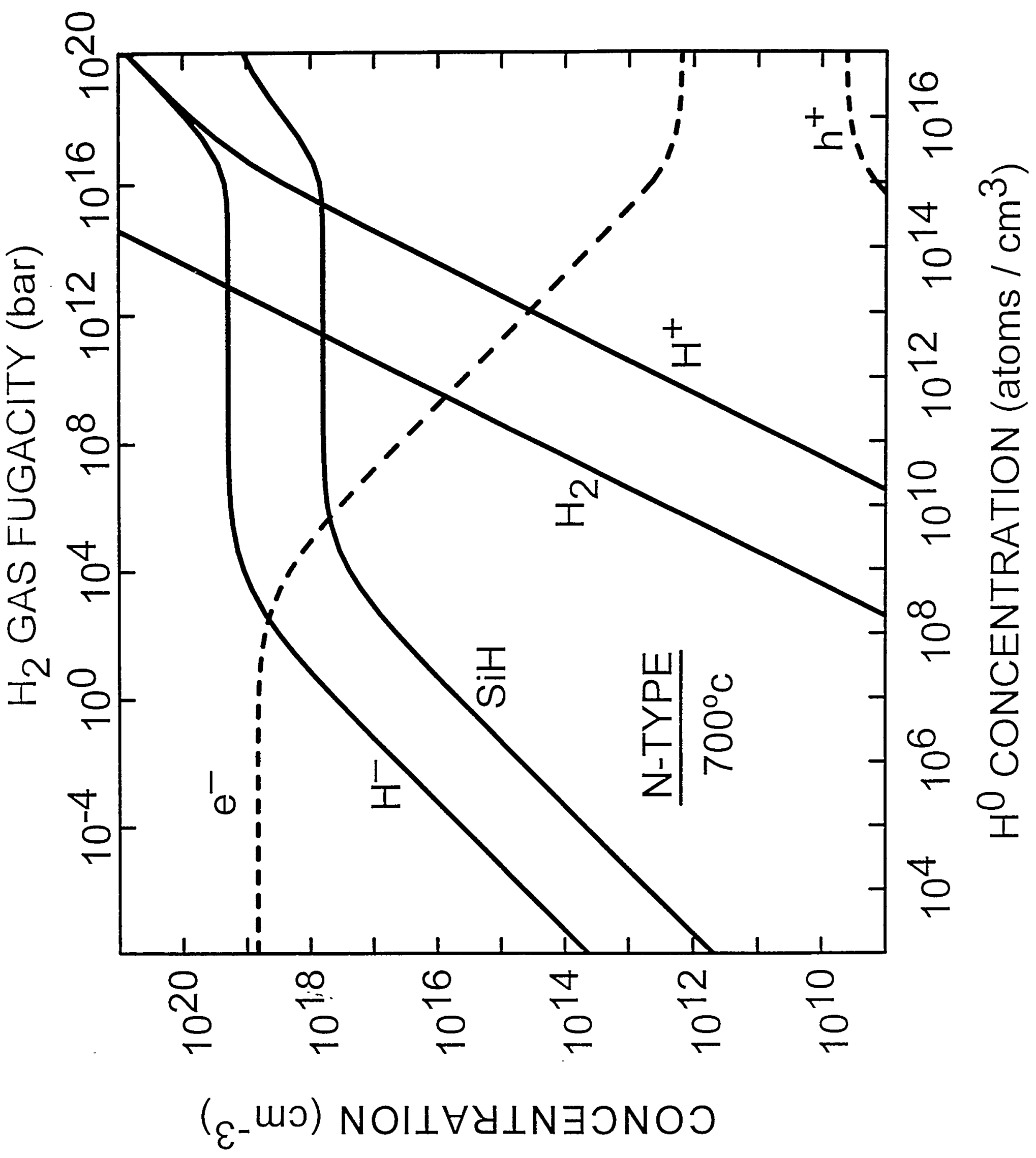




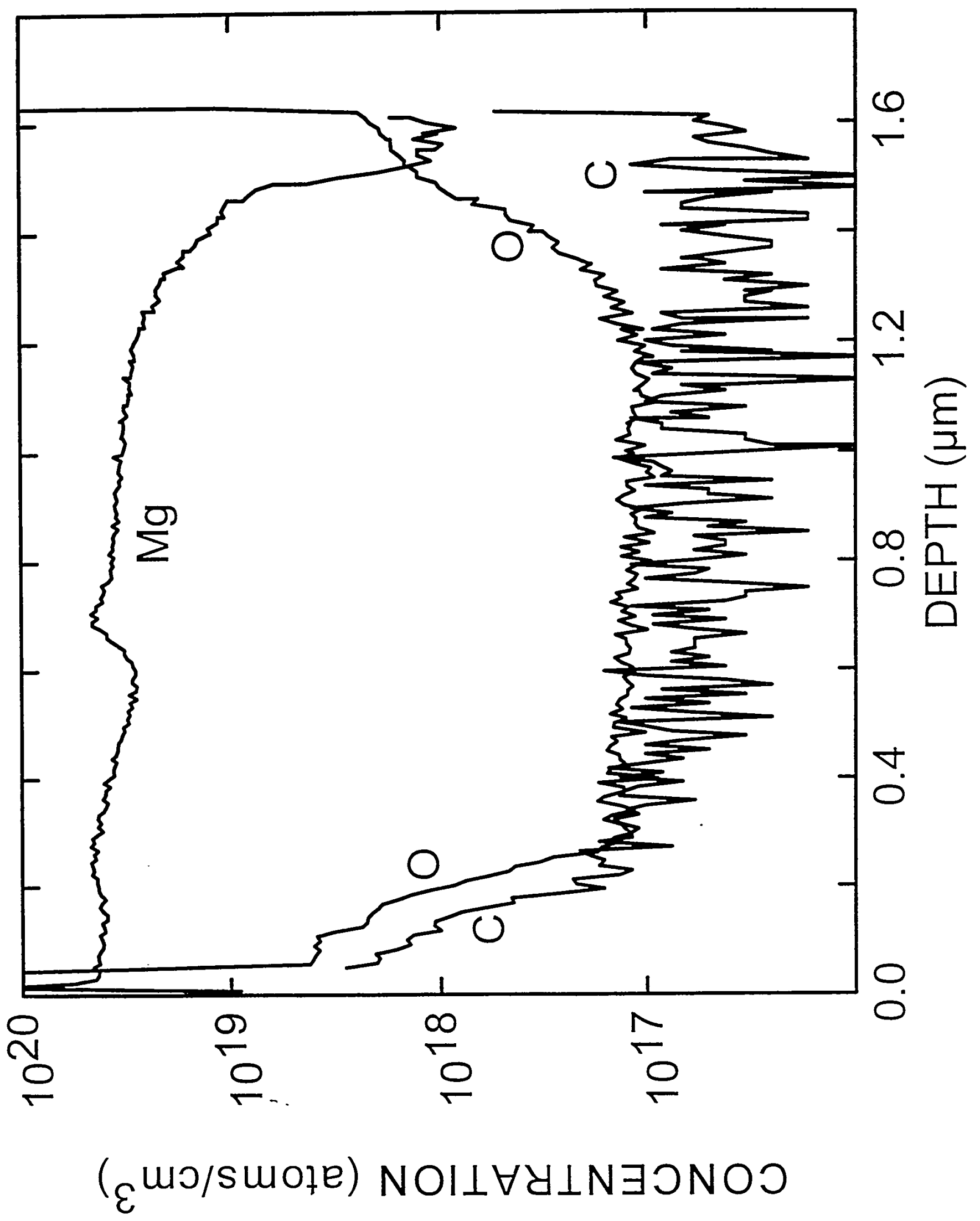




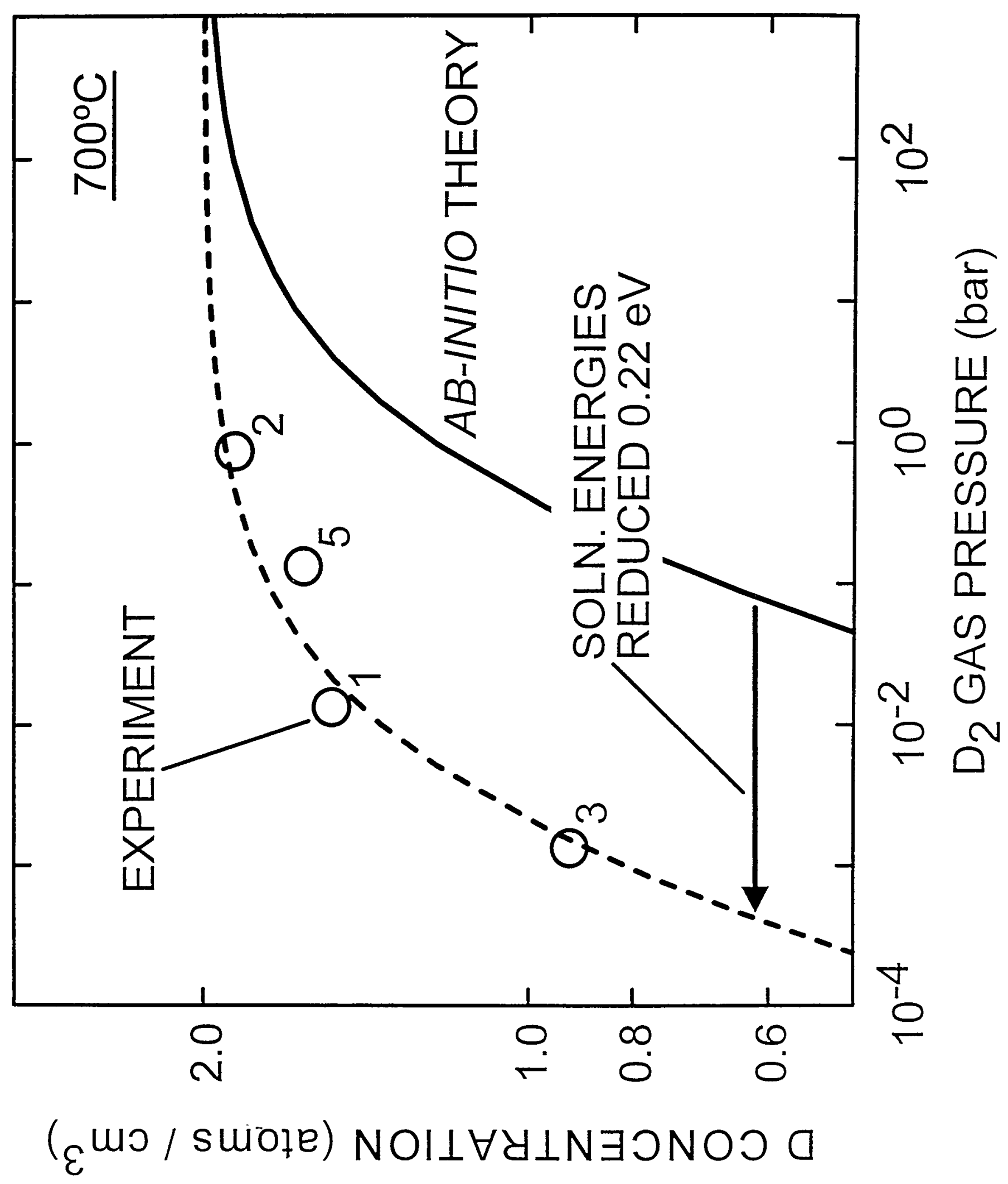




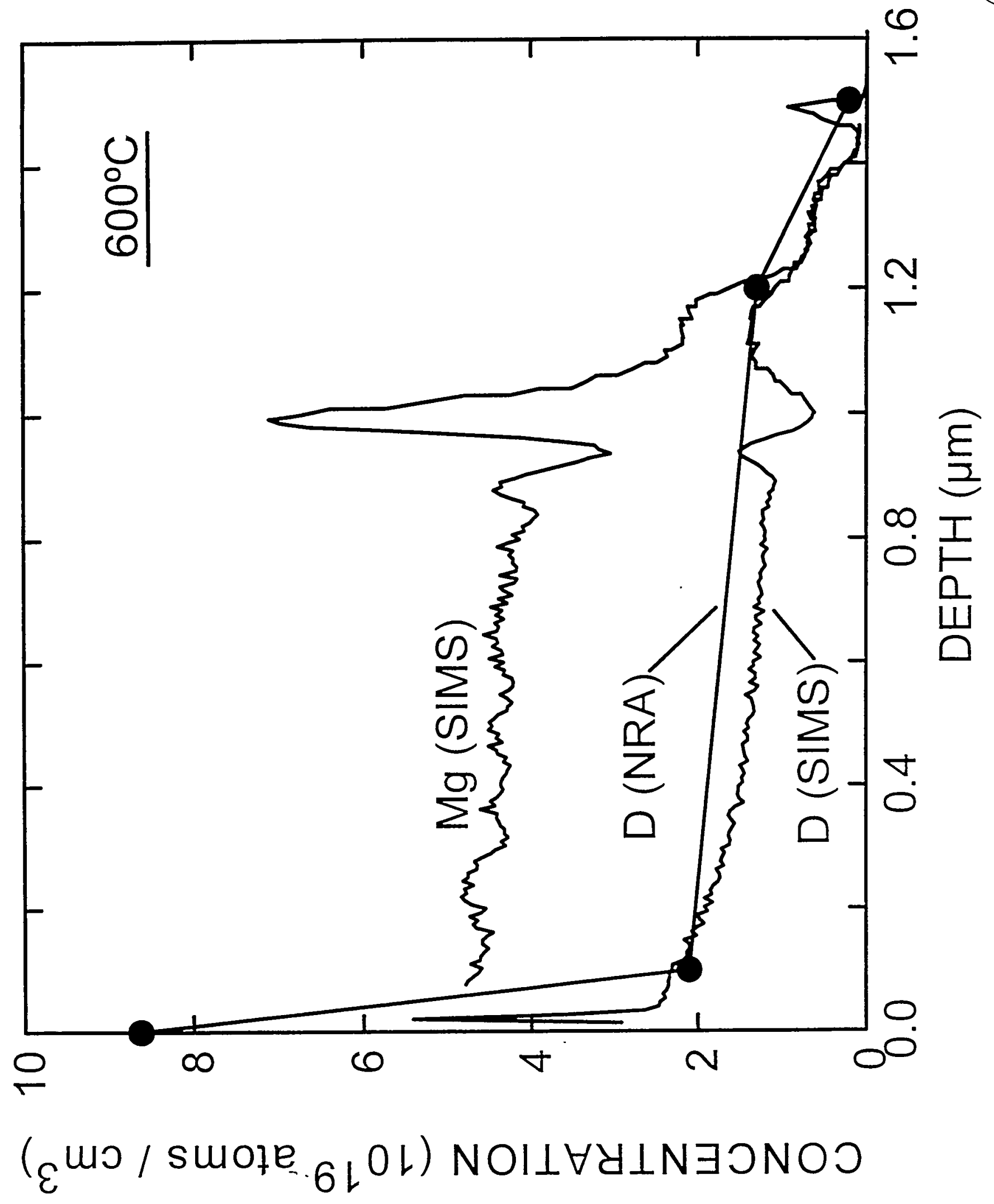




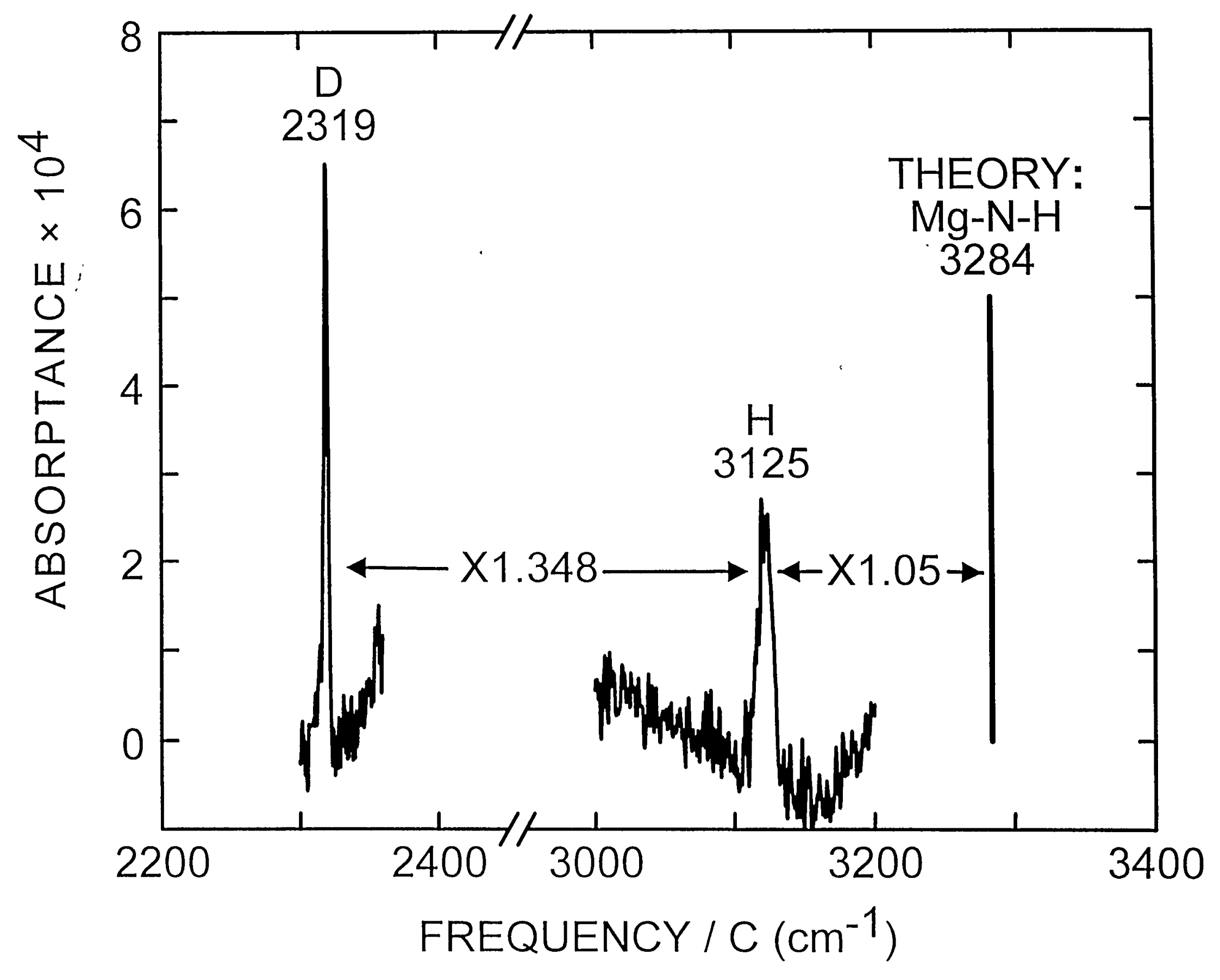




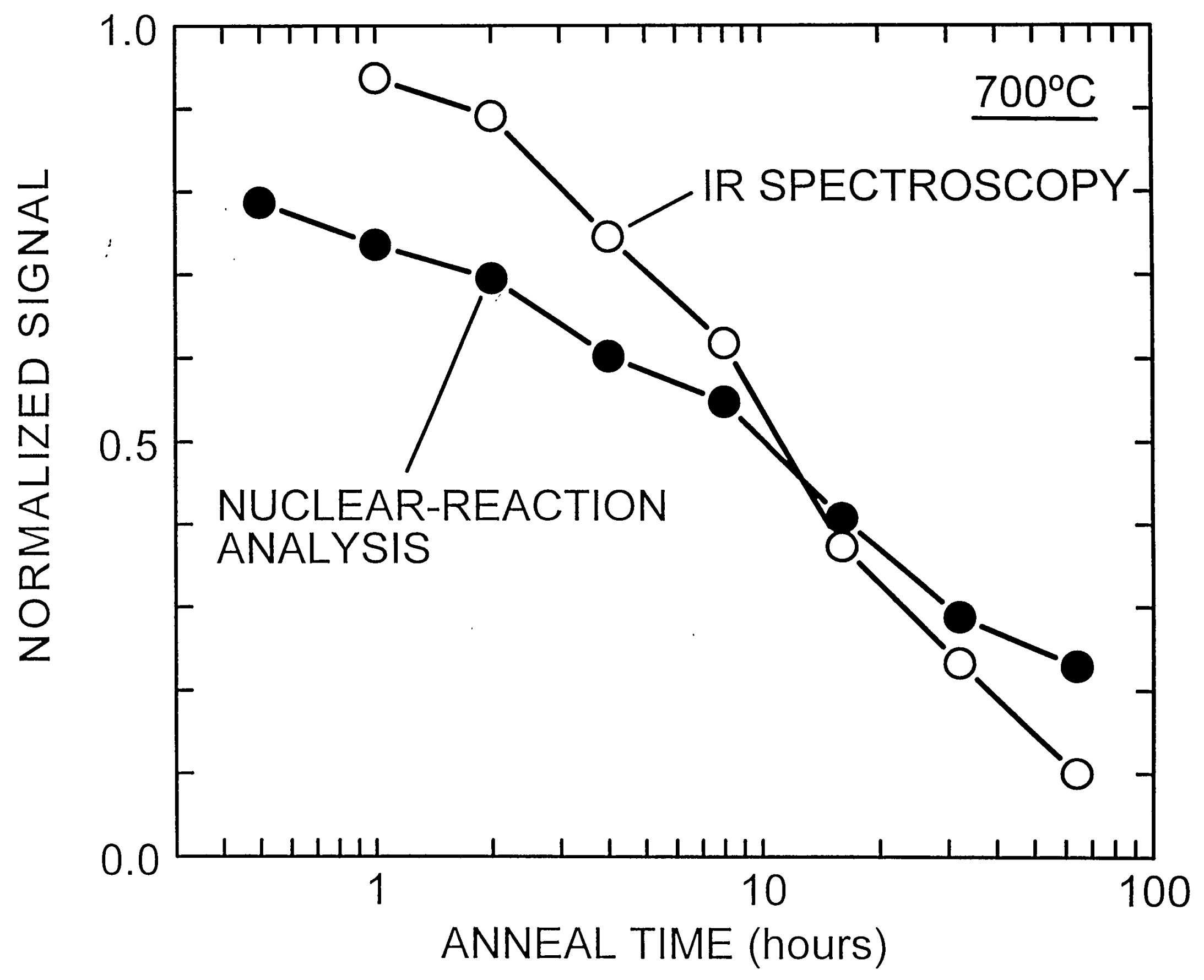

